\title{
Human Gut Microbiota: Toward an Ecology of Disease
}

Susannah Selber-Hnatiw, Belise Rukundo, Masoumeh Ahmadi, Hayfa Akoubi, Hend Al-Bizri, Adelekan F. Aliu, Tanyi U. Ambeaghen, Lilit Avetisyan, Irmak Bahar, Alexandra Baird, Fatema Begum, Hélène Ben Soussan, Virginie Blondeau-Éthier, Roxane Bordaries, Helene Bramwell, Alicia Briggs, Richard Bui, Matthew Carnevale, Marisa Chancharoen, Talia Chevassus, Jin H. Choi, Karyne Coulombe, Florence Couvrette, Samantha D’Abreau, Meghan Davies, Marie-Pier Desbiens, Tamara Di Maulo, Sean-Anthony Di Paolo, Sabrina Do Ponte, Priscyla dos Santos Ribeiro, Laure-Anne Dubuc-Kanary, Paola K. Duncan, Frédérique Dupuis, Sara El-Nounou, Christina N. Eyangos, Natasha K. Ferguson, Nancy R. Flores-Chinchilla, Tanya Fotakis, Mariam Gado Oumarou H D, Metodi Georgiev, Seyedehnazanin Ghiassy, Natalija Glibetic, Julien Grégoire Bouchard, Tazkia Hassan, Iman Huseen, Marlon-Francis Ibuna Quilatan, Tania Iozzo, Safina Islam, Dilan B. Jaunky, Aniththa Jeyasegaram, Marc-André Johnston, Matthew R. Kahler, Kiranpreet Kaler, Cedric Kamani, Hessam Karimian Rad, Elisavet Konidis, Filip Konieczny, Sandra Kurianowicz, Philippe Lamothe, Karina Legros, Sebastien Leroux, Jun Li, Monica E. Lozano Rodriguez, Sean Luponio-Yoffe, Yara Maalouf, Jessica Mantha, Melissa McCormick, Pamela Mondragon, Thivaedee Narayana, Elizaveta Neretin, Thi T. T. Nguyen, Ian Niu, Romeo B. Nkemazem, Martin O'Donovan, Matthew Oueis, Stevens Paquette, Nehal Patel, Emily Pecsi, Jackie Peters, Annie Pettorelli, Cassandra Poirier, Victoria R. Pompa, Harshvardhan Rajen, Reginald-Olivier Ralph, Josué Rosales-Vasquez, Daria Rubinshtein, Surya Sakr, Mohammad S. Sebai, Lisa Serravalle, Fily Sidibe, Ahnjana Sinnathurai, Dominique Soho, Adithi Sundarakrishnan, Veronika Svistkova, Tsolaye E. Ugbeye, Megan S. Vasconcelos, Michael Vincelli, Olga Voitovich, Pamela Vrabel, Lu Wang, Maryse Wasfi, Cong Y. Zha and Chiara Gamberi *

Department of Biology, Concordia University, Montréal, QC, Canada

\section{OPEN ACCESS}

Edited by:

Mike Taylor,

University of Auckland, New Zealand

Reviewed by:

Michael G. Surette,

McMaster University, Canada

Nicola Segata

University of Trento, Italy

*Correspondence:

Chiara Gamber

chiara.gamberi@concordia.ca
Composed of trillions of individual microbes, the human gut microbiota has adapted to the uniquely diverse environments found in the human intestine. Quickly responding to the variances in the ingested food, the microbiota interacts with the host via reciprocal biochemical signaling to coordinate the exchange of nutrients and proper immune function. Host and microbiota function as a unit which guards its balance against invasion by potential pathogens and which undergoes natural selection. Disturbance of the microbiota composition, or dysbiosis, is often associated with human disease, indicating that, while there seems to be no unique optimal composition of the gut microbiota, a balanced community is crucial for human health. Emerging knowledge of the ecology of the microbiota-host synergy will have an impact on how we implement antibiotic treatment in therapeutics and prophylaxis and how we will consider alternative strategies of global remodeling of the microbiota such as fecal transplants. Here we examine the microbiota-human host relationship from the perspective of the microbial community dynamics.

Keywords: human gut microbiota, host-microbe interactions, dysbiosis, disease, gut ecology 


\section{FOREWORD}

This review is the result of a pedagogic initiative undertaken during a third year Microbiology course at Concordia University in Montréal. The project's aim was to study the web of interactions between the human host and its gut microbiota by researching the latest discoveries and present it from the perspective of the microorganisms. The initiative also aimed at demonstrating to the students how to research the primary literature and write an analytical, comprehensive and balanced review. Choices on which original sources were cited were exclusively dictated by the pedagogic scope and reach of the course and in no way reflect considerations on the value of the contributions that were excluded. We therefore apologize to all the colleagues whose important research could not be cited due to such constraints.

\section{COMPOSITION OF THE HUMAN GUT MICROBIOTA}

The community of microorganisms residing in the human gastrointestinal (GI) tract, the GI microbiota, is composed of about one thousand commensal, and/or symbiotic microbial species among which Viruses (including bacteriophages), Bacteria, Archaea, and unicellular eukaryotes, comprising Fungi and other non-bacterial and non-archaeal microbial species (Ley et al., 2008; Gerritsen et al., 2011; Lozupone et al., 2012; Keeney et al., 2014; Lagier et al., 2016). Difficulties in culturing some gut microorganisms and discrepancies between the relative species relationships observed in vivo and ex vivo has resulted in an initial underestimate of the number of species in the human gut microbiome, the list of microbial gene functions of the GI tract (Lagier et al., 2015). Technological advances enabling metagenomics and microbial identification via MALDI-TOF mass spectrometry and the more recent implementation of culturomics have expanded the known microbial community of the human microbiome (Gill et al., 2006; Ley et al., 2006; Seng et al., 2013; Hugon et al., 2015; Lagier et al., 2016). Under normal healthy circumstances GI tract microbes can perform beneficial tasks for the human host, e.g., food break down, synthesis of vitamins and biomolecules and interaction with its immune system. The GI environment, in turn, may support the growth, reproduction and longevity of the bacterial community (Lozupone et al., 2012; Browne et al., 2016). Changes in the gut environment from diet and host physiology, as well as ingested microbes, may create competition for resources that affect the resident microbiota and may re-shape the microbial community, which in turn may affect host physiology. Host energy, metabolism and immunity have been found to respond to cues from the GI microbiota and many human health conditions have been linked with particular compositions of the GI microbiome (Bäckhed et al., 2005; Robosky, 2005; Turnbaugh et al., 2006; Rohde et al., 2007; Hibbing et al., 2010; Sommer and Bäckhed, 2013).

The gut-associated microbiome was found to be relatively conserved among several vertebrates including human, mouse, and zebrafish and it was speculated that ancestral mammalian species as early as the Jurassic period, relied on their gut-microbes to support their mainly herbivorous diet (MacKie, 2002; Rawls et al., 2004; Ley et al., 2008). It has been proposed that throughout mammalian evolution carbohydrates became prominent energy sources and the acquisition of gut-microbes may have enabled a large fermentative platform to supply the host with essential biomolecules (MacKie, 2002; Gill et al., 2006; Ley et al., 2008; Conlon and Bird, 2014). Constantly shaped by its interaction with the host, the human GI microbiota plausibly diverged from other microbial communities found in nature (Thaiss et al., 2016a). Consistent with this possibility, culture-free genetic profiling of the $16 \mathrm{~S}$ ribosomal (r) RNAs revealed major differences between free-living, or non-animal-associated, microbial communities and gut-associated microbiomes (Ley et al., 2008; Lagier et al., 2016). The microbiota and the host co-evolve with each other, albeit at different speed. Experiments in murine models provide growing evidence of deep relationships between the GI microbiota and the host physiology and gene expression (e.g., Stappenbeck et al., 2002; Round and Mazmanian, 2009; Dalmasso et al., 2011; Ghosh et al., 2011; Larsson et al., 2012; Reinhardt et al., 2012; Thaiss et al., 2016a). The adult GI microbiota was found to have a large inter-individual variation, with over 1,000 different bacterial species (Qin et al., 2010; Guinane et al., 2013). Archaea (especially the genus Methanobrevibacter) and fungi (phyla Ascomycota and Basidiomycota) also characterize a large portion of the human GI microbiome (Hoffmann et al., 2013). 16S rRNA analyses have revealed that more than $90 \%$ of bacterial species found within the gut are Bacteroidetes and Firmicutes, as well as Proteobacteria (Hold et al., 2002; Wang et al., 2003; Qin et al., 2010; Guinane et al., 2013). Proteobacteria and Bacteroidetes are Gram-negative bacteria involved in carbohydrate digestion, gut microbiome development, immune system modulation, and protection against colonization by pathogens (Russell et al., 2014). Some Firmicutes are Grampositive bacteria that also digest carbohydrates (Berry, 2016). Human-associated Archaea, among which Methanobrevibacter smithii found in almost $96 \%$ of healthy subjects, synthesize methane from $\mathrm{H}_{2}$ produced by bacterial catabolism (Hoffmann et al., 2013; Lurie-Weinberger and Gophna, 2015). Humanassociated fungal species include Saccharomyces, Candida, and Cladosporium, and several low-abundance strains (Hoffmann et al., 2013). M. smithii, Saccharomyces, and Candida were frequently found together in individuals having carbohydraterich diets (Hoffmann et al., 2013). While Candida remains asymptomatic in many individuals, immuno-suppression and/or antibiotic treatment may promote outgrowth and niche specific invasion throughout host tissues and mucosal sites (Huffnagle and Noverr, 2013). The GI microbiota appears sustained through complex interaction networks between the main phyla with the observed microbial proportions, likely reflecting the range of reciprocal exchanges needed for the dynamic physiological balance of both microbiota and the host (Qin et al., 2010; Cho and Blaser, 2012; Lagkouvardos et al., 2017). The GI microbiota also appeared relatively resilient and stable (Faith et al., 2013; Schloissnig et al., 2013) which seemed to suggest the possibility of developing new biomarkers for diagnostics and possibly for therapeutic purpose. Within single individuals, the environment 
changes along the GI tract, thus different microbes and population densities are found in a continuum along the different regions, reflecting their adaptation to distinct $\mathrm{pH}$, enzymatic conditions, anatomical structures, and physiology (Schneeman, 2002). For example, the $\mathrm{pH}$ in the mouth is close to neutral and the saliva contains enzymes inhibiting bacterial growth, while the stomach is extremely acidic $(\mathrm{pH} 2)$. The $\mathrm{pH}$ gradually increases in the small intestine and the colon ( $\mathrm{pH} 4-5$ and 7 respectively, Evans et al., 1988). Analyses of the human microbiome by the Human Microbiome Project revealed that, besides the dominant phyla, Bacteroidetes and Firmicutes, there was a great variation in relative composition of the microbiota, both in phyla-genus distributions, as well as individual differences that were initially grouped into different enterotypes (HMPC, 2012a,b). In the upper digestive tract stomach and small intestine, dwell abundant aerobic and facultative anaerobic species, while in the lower GI tract reside anaerobic species. In addition, functionally redundant species were found in multiple niches of the GI tract (Sommer and Bäckhed, 2013; Lozupone et al., 2012; Browne et al., 2016). As studies were extended to more and more subjects it became increasingly clear that individual variability was higher than anticipated and there was a need to revise the enterotype concept from one of fixed categories to one of a continuum along multiple dimensions (Knights et al., 2014). Interestingly, reanalyses of a sample time course from a single individual revealed that the GI microbiome may change enterotype, presumably indicating its adaptive capacity (ib.).

That no unique or discrete formula for a "healthy microbiota" seems to exist may reflect microbial functional redundancy enabling multiple species to play similar roles in the microbiotahost relationship. Other factors may also contribute, such as genetics and diet (Turnbaugh et al., 2007; Qin et al., 2010). In the context of the relationship between host and microbiota it seems advantageous that a healthy microbiota be able to carry out certain metabolic functions, such as providing short chain fatty acids (SCFA) to the intestinal epithelial cells. Metagenomic analysis showed that gene functionality of healthy microbiota appears indeed similar across individuals (HMPC, 2012b). Recent metabolomics studies have also revealed diverse interindividual profiles that promise to yield biomarkers for various diseased states (reviewed in Vernocchi et al., 2016). Relative balance among different microbial groups seems important for the host health and pathological alterations of such balance are defined as dysbioses (Tamboli et al., 2004). Regardless of its cause, dysbiosis correlated with various pathological conditions of the host, such as Inflammatory Bowel Disease (IBD), Type 1 Diabetes, Rheumatoid Arthritis (RA), asthma and obesity (reviewed in Keeney et al., 2014) and there is suggestive evidence that the gut microbiota may also be implicated in cancer (Ray and Kidane, 2016; Wroblewski et al., 2016; Yamamoto and Matsumoto, 2016) and may at least influence certain mental health conditions via the gut-brain axis (Moos et al., 2016; Mu et al., 2016; Obata and Pachnis, 2016).

Because of its enormous surface separating digesting food from the body and its role in nutrient absorption, the intestine is a fundamental barrier for the integrity and health of the organism, which is constantly patrolled by the immune system. In its complex synergy with the host's immune system, the
GI microbiota stimulates and is in turn stimulated by innate immunity, a balance that can be altered by pathogens trying to access the riches of the intestinal ecological niche (Thaiss et al., 2016b). During infection innate immunity and the resident microbiota cooperate to displace the pathogens actively via antimicrobial molecules and passively by crowding the niche and impeding the pathogen attachment to the gut lining. Simultaneously, the host-microbiota preferential relationship is promoted by secreted fucosylated molecules on the surface of the intestinal epithelial cells that favor resident microbes (Pickard et al., 2014).

We now realize the enormous impact the gut microbiota has onto human health and it has become an intensely studied subject, with a wealth of information being produced. This review examines recent discoveries about the diverse relationships between the human host and its microbiota from the perspective of the biological interactions of mutualistic symbiosis and/or commensalism between microorganisms and their human host (Figure 1). As we discover the many nuances of these complex connections and the underlying biomolecular associations, we raise questions about the partners' autonomy in the hostmicrobiota relationship. The holobiont theory describes the hostmicrobiota as a single biological unit, called the holobiont, which functions dynamically and appears to be subjected to evolution, rather than-or possibly in addition to-the individual species composing it (Bordenstein and Theis, 2015). Despite their poly-genomic composition, the deeply symbiotic relationships that have persisted among hosts and microbes across many groups and over time was used to define a consortium of interactions suspected to be cohesive with respect to selection processes (Booth, 2014; Bordenstein and Theis, 2015). Still controversial, the concept of the hologenome (i.e., the gene ensemble comprising a host and microbe syndicate) relies on cooperative integrated features of the host-microbiome partners with high fidelity of co-transmission, the latter being essential for being subjected to selective pressure (Zilber-Rosenberg and Rosenberg, 2008; Gilbert et al., 2012; Rosenberg and ZilberRosenberg, 2013; Douglas and Werren, 2016). Appealing for its inclusion of the functional relationships between host and microbiota, the holobiome concept is difficult to apply in the case of horizontally acquired symbionts, which do not have cohesive genomes with respect to different individuals (Douglas and Werren, 2016). Rare examples may include the endosymbiotic acquisition of nuclear organelles, which would be, however, an integrated part of a hologenome and not an entire microbiome (Douglas and Werren, 2016). As such, the holobiont and hologenome concepts have demonstrated poor research utility (Douglas and Werren, 2016).

\section{FUNCTIONS OF THE GI MICROBIOTA: NUTRIENT PROCESSING AND AVAILABILITY}

The GI microbiota contributes to the host's digestion by making carbohydrates available (Stecher, 2013; Conlon and Bird, 2014). Among the resident bacteria, species belonging to the phyla Bacteriodetes and Firmicutes can ferment undigestible carbohydrates, the fiber, to produce short chain fatty acids 


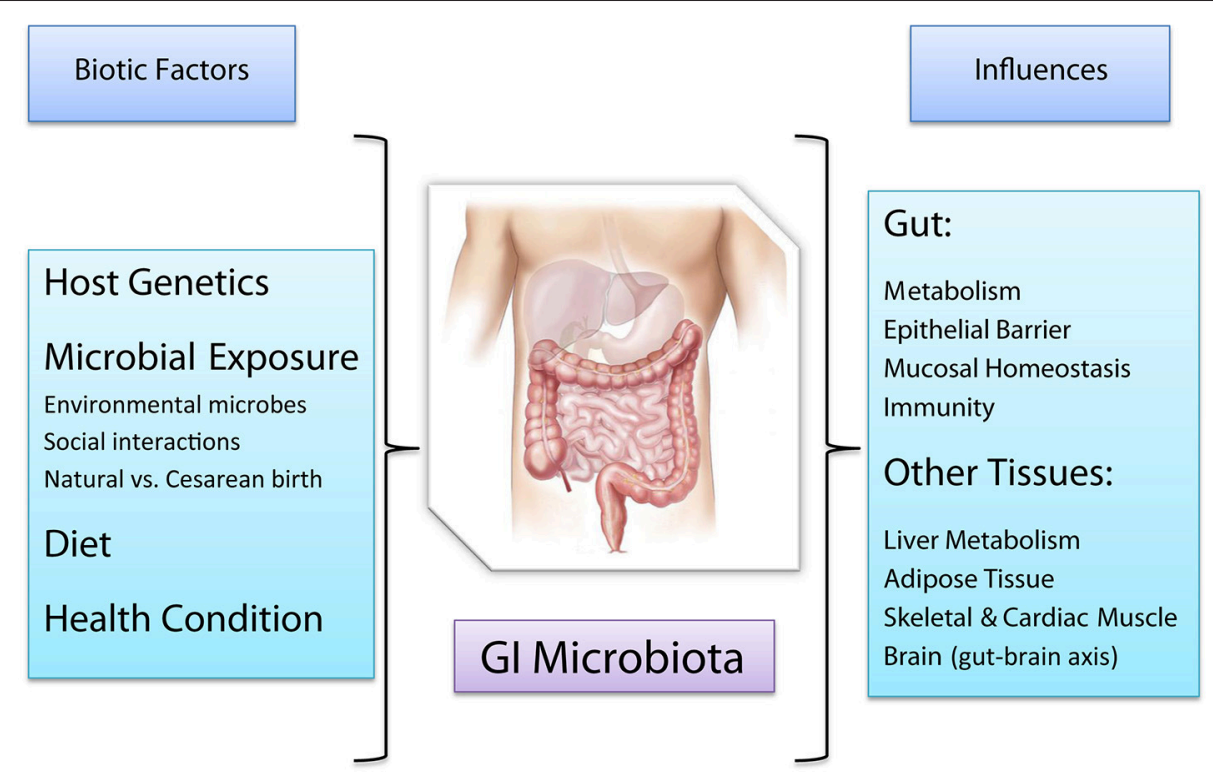

FIGURE 1 | Factors affecting the human Gl microbiota and host functions affected, either directly or indirectly, by the Gl microbiota.

(SCFAs), branched fatty acids, lactate, ethanol, $\mathrm{CO}_{2}$, and $\mathrm{H}_{2}$ which are then utilized by secondary fermenters, by the host, or excreted (Cummings et al., 1989; Belenguer et al., 2006; Flint et al., 2008; Fischbach and Sonnenburg, 2011; Sheridan et al., 2016; Patrascu et al., 2017). Of note, microbiota-produced SCFA constitute the main energy source of the intestinal epithelial cells (Topping and Clifton, 2001; Louis et al., 2010). Bacteria in the human gut microbiota can also synthesize beneficial vitamins such as folate, biotin, and vitamin K (Cummings and MacFarlane, 1997) and neutralize potentially carcinogenic compounds such as pyrolysates (Morotomi and Mutai, 1986). Gut bacteria detect available polysaccharides and activate different metabolic utilization pathways. In the case of the well-studied Bacteroidetes and the Firmicutes family Lachnospiraceae, these enzymes are encoded by multiple polysaccharide utilization loci (PULs, Bjursell et al., 2006; Martens et al., 2011; Sheridan et al., 2016) conferring the ability to utilize different glycans as carbon sources, which may allow trophic diversification, moderate species competition and facilitate distal gut colonization (Bjursell et al., 2006; Martens et al., 2011; Sheridan et al., 2016). The GI lumen, with its over 200 grams of digested contents, provides a diverse and competitive microbial environment for both mutualistic and pathogenic microorganisms. Successful colonization of a species acquired from the environment may depend on the ability to utilize differential nutrient sources, perform chemical sensing, and coordinate gene expression in favorable ways (Lozupone et al., 2008; Pacheco et al., 2012; Patrascu et al., 2017). Moreover, the presence of "keystone species" with rare metabolic capabilities may generate energy and cross-feed other microbial community members (Ze et al., 2012, 2013). Host genetics, food availability, dietary modifications, and resident microbes will influence contents and environment of the GI tract, conceivably affecting each microbial species differentially, and potentially shaping both species representation and numerical abundance of the community members. These models seem to agree with the results of both observational studies that correlated diet with microbiota composition in individuals from different geographical locations (De Filippo et al., 2010; Yatsuneko et al., 2012; Schnorr et al., 2014) and of human studies employing controlled diets (Walker et al., 2011; Martinez et al., 2013; David et al., 2014; O'Keefe et al., 2015). Because of the impossibility to experimentally control variables such as the individuals different genetic makeup and individual microbiota composition, the conservative interpretation is that the microbiota was found to respond to dietary changes quickly, with some microbial communities more readily responding to such changes than others (Walker et al., 2011; Salonen et al., 2014). These dynamics are reminiscent of other microbial expansions in natural habitats (e.g., algal blooms) where excess of certain nutrients may favor the overproliferation of definite groups and outcompete other species in the same environment, reducing overall microbial diversity, and highlighting the potential to adapt ecological models for studying the GI microbiota.

Because of its dynamic nature, the microbiota could potentially be manipulated via dietary changes and administration of either antibiotics or probiotics to, respectively, increase or decrease microbial numbers and diversity. Probiotics can be aliments such as traditional fermented foods rich in live microorganisms (e.g., sauerkraut, kimchi, yogurt) or supplements (Voreades et al., 2014; Zuk, 2014) which have been used to promote proliferation of beneficial microbes and organismal diversity at the expense of selected pathogens in diseases accompanied by dysbiosis (Saxelin et al., 2010). Prebiotics on the other hand, provide molecules to stimulate and support resident GI tract bacteria (Bouhnik et al., 2004, 
2006; Ramirez-Farias et al., 2009; Davis et al., 2011; Dewulf et al., 2013). Probiotic administration was found to increase gut microbial diversity in obese patients up to a month (Kadooka et al., 2010; Wassenaar et al., 2014) suggesting the feasibility of directing changes in the microbial imbalance of the GI tract by outcompeting harmful bacteria (Rigottier-Gois et al., 2015). A stimulating prospect, GI microbiota manipulation reminds us that our incomplete knowledge of the GI microbiota ecology and its intricate relationships with the host may result in accidentally favoring opportunistic pathogens or provoking pathological responses (Mukherjee et al., 2013). On the other hand, microbial competition could in principle be employed strategically to limit or eliminate pathogens in alternative to conventional antibiotic treatments, with the added advantage of preventing horizontal transfer of antibiotic resistance genes.

\section{IMMUNITY AND GI MICROBIOTA}

Early development of the gut microbiota has been shown to be important for normal immune response and to prevent autoimmune disease (Round and Mazmanian, 2009). Because the relationship between host immune system and microbiota has been recently reviewed thoroughly (Belkaid and Harrison, 2017) and most of our co-authors had not yet studied Immunology, a fourth year course, here we will just recall a few concepts for completeness and refer interested readers to Belkaid and Harrison. The GI microbiota is essential for the maturation of the immune system, which is composed by both adaptive and innate immune responses. Innate immunity relies on the physical barrier of the epithelia, circulating chemicals and specialized cells to quickly recognize a broad range of foreign antigens on cells with pathogenic potential and eradicate them (Reece et al., 2011; Lupfer et al., 2014). On the other hand, adaptive immunity deals with pathogens through a slower, albeit longlasting, response via stimulation of lymphocytes expressing specific cross-reactive antibodies (Lupfer et al., 2014). Displaying the largest density of epithelial cells (EC) in the body, the GI tract receives more antigens than any other body parts through ingested foods and the interactions with the microbiota (Kuhn et al., 2014; Shi et al., 2017). The latter contributes to maintenance of the intestinal barrier at various levels. For example, it stimulates the goblet cells to produce the mucus lining the intestine (Kandori et al., 1996); it is involved in determining the specificity of the luminal immunoglobulins A, which recognize antigens in potential pathogens (Brandtzaeg et al., 2006) and contrasts their adhesion for effective clearance (Johansen et al., 1999; MacPherson and Uhr, 2004). Because every microorganism in the gut, both commensal and foreign, can (and will) be targeted by the host's immune system, it may seem surprising that healthy interactions between the specialized intestinal phagocytic macrophages and the microbiota normally do not cause release of pro-inflammatory cytokines IL-1 and TNF and inflammation (Smythies et al., 2005). How host immunity avoids being overpowered is only partly known and actively being investigated. Because of the high selectivity of the gut environment, only microbes able to establish a "dialog" with the host can colonize the microbiota, while the others will be eliminated by the combined action of the host's immunity and the resident microbes, some of which can synthesize bacteriocins which actively target competing species (Corr et al., 2007; Hibbing et al., 2010; Patwa et al., 2011; Dobson et al., 2012). Interestingly, germ-free mice were found to contain fewer circulating lymphocytes (Wostmann et al., 1970) suggesting that GI microbes may also affect adaptive immunity.

\section{NUTRIENTS, BACTERIAL COMPETITION, AND COLONIZATION}

The mammalian gut environment is fairly protected and has relatively stable temperature, yet it is dynamic and competitive, imposing a strong evolutionary pressure onto the microbes. The resident microbiota is constantly sensing and integrating information on nutrients and microbial content of digested food and drinks, the glycans projecting from the surface of intestinal cells, and the overall health and immunity of the host. The tight interaction web between host and its GI microbiota allows resident microbial communities to monopolize nutrients and adhesion sites and establish a molecular and genetic "dialog" with the host, simultaneously blocking newcomer, potentially pathogenic, microorganisms from accessing the high energy sources they need to replicate and establish themselves in the community (Stecher, 2013). To successfully colonize the intestine, microorganisms must withstand fast changes in nutrients, high osmolarity and stomach acidity, bile salts, protective mucus, and microbial competition. Antigens detected in unfamiliar bacteria cause phagocytosis from the host's cells. Bacteria that can avoid phagocytosis can begin colonization by proliferating initially in small niches. These localized microbial blooms may cause resource competition and transiently alter gut ecology, although the long-term outcome of the inter- and intraspecific bacterial competition allowing the stable colonization of the new species or its demise likely depends on the context of resource availability, interactions with the microbial species in the same trophic level as well as the host's immunity (de Muinck et al., 2013). Large scale bacterial invasions, as may result from the ingestion of contaminated food or water, may severely compromise the resident microbiota, reducing its diversity in favor of the expansion of selected strains.

The host's nutritional status may affect both microbiota diversity and microbial colonization. How well strains can adapt and access nutritional resources can contribute to reproductive success of both resident microbes and foreign invading species. Upon introduction into the mammalian gut, Escherichia coli and other Gram-negative bacteria were observed to undergo many rounds of mutation, producing both adaptive and deleterious variants that spread through the population simultaneously in so called "soft sweeps" (Barroso-Batista et al., 2014). Should any mutation provide survival advantage (or possibly by chance in small populations) it could become established and compete with all others for fixation. In a germ-free mouse model that recapitulates and simplifies the complexity of the natural ecological conditions, inoculation of model E. coli strain MG 
1655 showed the appearance of the first beneficial mutation just 2 days after invasion, which lead to quick adaptation to the murine host. MG1655 carried loss of function mutations in the gat and srl operons (which encode the biochemical machinery for utilizing galactidol and sorbitol respectively) enabling the mutants to utilize alternate carbon sources in conditions of high competition for nutrients (ib.). Another adaptive mutation in the $\operatorname{arc} A$ gene critically enabled switching between aerobic and anaerobic respiration depending on oxygen levels (ib.). In this system, the temporal unfolding of the colonization process appeared influenced by strong selection as well as the contributions of multiple small effect mutations in a process that could surprisingly be repeated, which may intriguingly suggest the existence of predictable driving forces (Lourenço et al., 2016). The capacity of utilizing ready-made metabolic intermediates may also be advantageous for microbes. Vitamin $\mathrm{B}_{12}$ is a cofactor required for metabolic processes in over $70 \%$ of Gram-negative bacteria whose de novo synthesis requires 30 steps. Combinations of metabolically economic systems of transmembrane "corrinoid receptors" for absorbing $\mathrm{B}_{12}$ itself or its analogs (collectively termed corrinoids) have been found in many species and appeared to increase the cell's fitness, depending on corrinoid availability (Degnan et al., 2014; Sonnenburg and Sonnenburg, 2014).

Besides mutations affecting nutrient uptake and utilization, mutations in genes with regulatory functions may also provide means of fine-tuning adaptation by affecting downstream pathways both additively and independently (Giraud et al., 2008). While phenotypic variants compete for survival and dominance within the same trophic level, both ecological context (e.g., other microbial species in the same trophic level, host genetics) and environmental resource availability may result in different colonization patterns dynamically and over time. Ex vivo studies of simplified models of GI microbiota found that, during the early colonization stages, both aerobic and facultative anaerobic E. coli strains could thrive until oxygen reserves were exhausted and obligate anaerobes strains took over (de Muinck et al., 2013). However, introduction of other bacterial species was found to change the outcome: Clostridium perfringens, naturally present in the gut microbiota, lowered environmental peptone levels, impairing the success of the anaerobes, which were more dependent on peptone than the aerobic strains (ib.). Host immunity appears to contribute to colonization. Considering the microbiota diversity in vivo, we expect that the microbial interaction web will be at least as complex as what has been observed in other environmental poly-microbial communities, with the added component of multiple layers of interaction with the host. In the context of this formidable, yet fascinating complexity, studies of murine models may not fully reproduce the species-specific interactions of the human microbiota with the human host (Chung et al., 2012; Du et al., 2015) yet may provide controlled experimental conditions in which genetic homogeneity and germ-free culturing conditions minimize the influence of compounding factors such as inflammation, thus facilitating the study of the molecular mechanisms of interaction between the host and either single species or controlled microbial mixtures (e.g., the simplified human microbiota, Becker et al.,
2011; Eun et al., 2014), whose knowledge contributes to our global understanding of the host-microbiota relationship.

\section{NUTRIENT NICHES FAVORING PATHOGENIC GUT COLONIZATION}

Resource acquisition is crucial for microbes (including pathogens) aiming at colonizing the competitive environment of the mammalian intestine and these species must overcome the inherent colonization resistance of healthy individuals (Van der Waaij et al., 1971; Faust et al., 2015). In healthy individuals competition for both nutrients and attachment sites make pathogens such as Clostridium difficile less likely to colonize the gut and become a burden to the host (Guarner and Malagelada, 2003). The enterohaemorrhagic E. coli strain O157:H7 found in undercooked meat and contaminated produce is responsible for many bacterial food poisoning cases in developed nations (Loftsdóttir et al., 2017). What makes O157:H57 successful is its ability to regulate gene expression in response to its surroundings. Commensal E. coli are found in the mucus layer, whereas O157:H57, along with non-pathogenic Bacteroides thetaiotaomicron, are found on the intestinal epithelium (Iversen et al., 2015). Rather than counterproductively competing for resources in the mucus layer, O157:H57 can colonize areas of high fucose availability on the intestinal EC (Pacheco et al., 2012). B. thetaiotaomicron cleaves fucose from host produced mucin, which activates the FusKR receptor in O157:H57 and the expression of virulence factors. Upon successful colonization of the intestinal epithelium, O157:H57 metabolizes carbon sources such as galactose, which are not being utilized by commensal E. coli.

Campylobacter jejuni, typically acquired through ingestion of uncooked poultry, causes a form of human gastroenteritis (Olson et al., 2008). A highly fermentative healthy microbiota generates steady supplies of organic acids such as acetate and lactate that constitute electron and carbon sources for downstream metabolism. C. jejuni was found to contain two completely redundant respiratory enzyme systems for growth on L-lactate, underscoring the evolutionary advantage of being able to grow on lactate (Thomas et al., 2011).

One of the best characterized examples of pathogenic bacterial infection is that of the members of the Salmonella genus, that utilize an arsenal of resources during their attempts at gut colonization. Salmonella enterica serovar Typhimurium (hereby referred to as S. Typhimurium) is a common Gram-negative microorganism of the Enterobacteriaceae family that causes typhoid fever and food poisoning. All Salmonella serotypes are disease causing in humans, but only certain ones are host specific (WHO, 2016). The dominant strain responsible for human pathogenicity is $S$. typhi, while $S$. Typhimurium, also pathogenic, is transmitted from animals to humans either directly or via contact or consumption of undercooked infected meat (WHO, 2016). In the initial phase of invasion, S. Typhimurium generates energy via the $h y b$ hydrogenase-mediated oxidation of $\mathrm{H}_{2}$, a readily available by-product of resident microbe metabolism (Lamichhane-Khadka et al., 2010; Maier et al., 2013, 2014). 
Because $h y b$ mutants displayed impaired growth, hyb function appears necessary for invasion. Moreover, $\mathrm{H}_{2}$ sequestration by an avirulent strain able to utilize $\mathrm{H}_{2}$, S. Typhimurium ${ }^{\text {avir }}$, could thwart S. Typhimurium colonization (Maier et al., 2013). Energetic strategies based on $\mathrm{H}_{2}$ utilization are also employed by other pathogens to gain purchase on the resident microbiota, among which Campylobacter, Shigella, and Yersinia (ib.). When nutrients are scarce, many bacteria become more motile as they forage for survival. Distinctively, nutrient abundance was found to stimulate a bistable response in S. Typhimurium in which a proportion of cells activated the expression of flagellar proteins becoming highly motile and continuing host invasion. The other cells, instead, remained non-motile and noninvasive, bypassed the host's inflammatory response and may fuel subsequent colonization bouts (Koirala et al., 2014). To gain advantage on the commensal species of the microbiota, $S$. enterica can release colicin Collb, a pore-forming toxin targeting the Enterobacteriaceae family and especially E. coli (Nedialkova et al., 2014). Because toxin synthesis is energetically expensive and Collb is toxic to Salmonella itself, only few cells in the population were found to secrete colicin (ib.). Interestingly, the success of a colicin invasion strategy may depend in part on nutrient availability, because the presence of iron caused conformational changes of the $E$. coli receptor, reducing its sensitivity to Collb (Pugsley and Reeves, 1976). Finally, S. enterica can form biofilms, robust bacterial sheets protected by a self-secreted polysaccharide matrix which can adhere to surfaces. Albeit likely to occur, we do not have experimental evidence of biofilm formation in vivo. If confirmed, such capacity may conceivably contribute to colonization (Chelvam et al., 2014). The capacity for Salmonella biofilm formation is encoded on several different plasmids, one being pRST98, whose expression is triggered by extracellular signaling molecules $\mathrm{N}$-acylhomoserine lactones, which are part of the quorum sensing system activated by bacteria in crowded populations (Liu et al., 2014).

\section{MICROBIOTA MANIPULATION OF HOST'S BEHAVIOR?}

While commensal GI microorganisms can extract nutrients from the food, they do require specific nutrients to thrive. During studies on the causative factors of obesity it was observed that the GI microbiota may modulate expression of taste receptors (Miras and le Roux, 2013; Avau et al., 2015; Avau and Depoortere, 2015; Murtaza et al., 2017), affect the vagus nerve which controls the gut-brain axis (Rhee et al., 2009; Bercik et al., 2012; Collins et al., 2012; Vaughn et al., 2017) and influence the release of toxins and neuro-transmitters (Kollai et al., 1994; Lyte et al., 2011; Clarke et al., 2014). In a small human study, probiotics were found to stimulate both number and diversity of gut microbiota in obese adults and reduced host cravings, raising the untested possibility that the subjects' eating preferences may have been modified (Kadooka et al., 2010). Initial attempts at probing this possibility in mice made use of either probiotics or antibiotics administration to alter the GI microbiota and observe changes in the hosts' eating patterns and food preferences, which appeared to correlate with the nutritional requirements of the current resident microbes (Alcock et al., 2014; Zuk, 2014). The ratio of Bacteroidetes to Firmicutes is often used as an indicator for body mass, with high ratio observed in lean individuals and low ratio in obese ones respectively (Bäckhed et al., 2004; Ley et al., 2005; Turnbaugh et al., 2006, 2007; Zhang et al., 2012; Evans et al., 2014; Lecomte et al., 2015; Shang et al., 2017). The Firmicute family Lachnospiraceae is responsible for producing SCFAs that can fuel the growth of other gut microbes and host epithelial cells, and may enhance the host's energy harvesting capacity, resulting in liver lipogenesis and triglyceride accumulation (Meehan and Beiko, 2014; Singh et al., 2015; Nehra et al., 2016; Shang et al., 2017). Consumption of certain food groups seemed to affect both the Bacteroidetes to Firmicutes ratio and the diversity in the gut, which in turn may influence the gut-brain vagal communication, potentially contributing to obesity (de la Serre et al., 2015; Sen et al., 2017). These intriguing results suggest that the microbiota may influence the host's eating preferences affecting its mood and satisfaction for certain food groups, possibly depending on the nutritional requirements of the members of the microbial community. Only supported by correlative evidence, this speculative scenario raises interesting points of reflection. Considering that each microorganism in the microbiota could potentially and competitively manipulate the host for its own benefit, a diverse microbiota would favor the host by lessening the intensity of the influence by any single microbial group. Conversely, a microbiota composed of fewer, more numerous groups may potentially exert a stronger influence on host eating behavior (Alcock et al., 2014), which would agree with the peculiar microbiota composition observed in certain eating disorders.

\section{THE MICROBIOTA IN FASTING AND MALNUTRITION}

Dynamically responding to environmental conditions, the microbiome responds to nutritional changes, including fasting and malnutrition (Arumugam et al., 2011; Flint et al., 2014). Because of ethical reasons the effects of starvation on the GI microbiota has only been studied in controlled settings in animal models. Several weeks of nutrient deprivation in fish, mice and toads displayed increased microbiome diversity; quails showed no change, and geckos a decrease (Kohl et al., 2014). Seasonal fasting can occur naturally, e.g., during molting of king and small penguins, when energy reserves whose deposition depends on gut function become essential for thermoregulation and producing new plumage. Molting penguins exhibited changes in microbiota composition, especially after prolonged fasting. King penguins displayed increased Proteobacteria during early molt, and decrease of both Proteobacteria and Bacteroidetes during late molt (Dewar et al., 2014). Conversely, in hibernating squirrels the normally dominant Firmicutes group contracted throughout hibernation. A small, representative bacterial population seeded the rebound of gut microbiota during the active months (DillMcfarland et al., 2014). These variable responses to starvation make it difficult to model the effects of nutrient deprivation 
in humans, which we can only observe in specific cases of malnourished individuals. Human moderate and severe acute malnutrition are significant global health issues. Respectively affecting $\sim 19 \%$ of children in Asia and 20 million children globally (WHO, 2007), they are leading causes of child mortality (Smith et al., 2013). Severe malnutrition is typically treated with nutrient-rich "ready-to-use therapeutic food," which reduces mortality, albeit children cannot fully recover even after body mass improvements, likely because of their immature microbiomes (Prentice et al., 2013; Tilg and Moschen, 2013; Subramanian et al., 2014). In fact, early gut microbiome development is particularly important in children, whose microbiota shifts as they grow and change diet (Bergstrom et al., 2014). Microbiota remodeling by antibiotic therapy improved survival of children with severe acute malnutrition (Trehan et al., 2013; Subramanian et al., 2014), however when the microbiome remained immature severe malnutrition re-occurred, suggesting that microbiome maturity may predict the long-term success of therapeutic food administration (ib.). Moreover, the enterotype appeared to contribute to the onset of severe malnutrition, an effect that could be reproduced by transplanting the human GI microbiota into gnotobiotic mice (Smith et al., 2013). Although current studies on human malnutrition are only observational, there are hopes that therapeutic remodeling of the GI microbiota may help eliminate malnutrition-associated mortality.

\section{MAINTAINING THE GI MICROBIOTA DURING ACUTE INFECTIONS}

During the host's response to pathogenic microorganisms initial anorexia can starve the pathogen while the host utilizes its own resources for resisting infection (Langhans, 2000). Anorexia could in principle also starve the microbiota; however, sophisticated preferential communication between the host and its microbiota was found to support the resident microbes during infection-induced stress. Lipopolysaccharides from the bacterial cell wall interact with and activate Toll-like receptors (TLRs) expressed on the membrane of intestinal macrophages. In mice TLR activation activated interleukin release and the fucosyltransferase 2 enzyme (Fut2) in the small intestine epithelial cells, resulting in fucosylation of certain membrane proteins (Pickard et al., 2014). Superficial L-fucose can be preferentially cleaved and utilized by the resident microbes (ib.). It was observed that Fut2 polymorphisms may confer susceptibility to Crohn's Disease (Rausch et al., 2011) and its mutation both reduced microbiota diversity (Patwa et al., 2011; Wacklin et al., 2011) and increased sensitivity to Candida albicans infections in mice (Hurd and Domino, 2004). Contrary to initial reports, the bacteria-host interaction was found to be insufficient, albeit necessary, to trigger fucosylation in intestinal epithelial cells (Goto et al., 2014). Two additional mechanisms were found to contribute to fucosylation, the first being mediated by the type 3 innate lymphoid cells residing in the mucosal lining, which produce interleukin-22 in response to the resident microbiota and induce Fut2 (ib). Reinforcing such mechanism, interleukin22 also induces expression of the antibacterial RegIII- $\gamma$ molecule (Satoh-Takayama et al., 2008; Sonnenberg et al., 2011; Tumanov et al., 2011). Finally, lymphotoxin $\alpha$, also secreted by ILC3, could induce fucosylation independently of the microbiota (Patwa et al., 2011; Goto et al., 2014).

\section{PATHOLOGIES WITH ALTERED GI MICROBIOME}

Because the GI microbiota interacts with the host immunity at multiple levels, dysbiosis may result in or be indicative of pathologies (Table 1). In fact, because of the complexity and reciprocity of the microbiota-host relationships it is debated whether the dysbiotic state may cause or be consequence of the pathology (Butto and Haller, 2016). Alterations of the composition of the GI microbiota may occur upon exposure to antibiotics, drugs, or radiation (Wallace et al., 2011; Nam et al., 2013; Keeney et al., 2014), stress or infections (Moloney et al., 2014), and nutritional changes (Griffin et al., 2017). Asthma and inflammatory bowel diseases (IBD) were both found to be directly affected by the interactions between the gut microbiota and host immunity.

\section{Asthma}

Asthma is a chronic disease that causes inflammation of the airways (NIH, 2014). In asthma, both low diversity and a numerically reduced gut microbiota eventually appears to induce allergy and lung hypersensitivity (Table 1, Ferreira et al., 2014). Common symptoms include wheezing, coughing, difficulty breathing, or shortness of breath with variable severity. It has been proposed that asthma prevalence may be increasing in Western countries because of lifestyle modifications that impoverish the microbiota, including excessive hygiene, liberal use of antibiotics and a high-fat diet (Strachan, 1989; WillsKarp et al., 2001; Vercelli, 2009, 2010; Von Mutius and Vercelli, 2010; Allan and Devereux, 2011; Korpela et al., 2016). However, research is still developing about the long term effects of antibiotic use on the microbiota (WHO, 2014; Korpela et al., 2016). Epidemiological studies indicated that early life exposure to microbes helps preventing allergic diseases, leading to the "hygiene hypothesis" (Wills-Karp et al., 2001). This theory speculates that reduced microbial exposure due to aggressive cleaning, disinfection, urbanization, and impoverished diets may lead to altered microbiota and inadequate immune function (Ferreira et al., 2014). The findings of Weber et al. (2015) suggest that home or personal cleanliness may in fact have no impact on the development of asthma. Rather, a variety of microbial exposures may determine microbiota composition, possibly leading to the development of asthma in predisposed individuals (Ege et al., 2011, 2012; Weber et al., 2015). Asthmatic children were found to have prevalence of the pathogenic $C$. difficile and low abundance of non-pathogenic Bifidobacterium in their intestinal microbiota, which may reduce immune function in the airways (Kalliomäki et al., 2001a,b) and potentially contribute to disease chronicization. 
TABLE 1 | Diseases associated with Gl microbiota abnormalities.

\begin{tabular}{ll}
\hline Disease & Features \\
\hline Rheumatoid arthritis & $\begin{array}{l}\text { Chronic, inflammatory auto-immune disorder displaying reduced Bifidiobacteria } \\
\text { and Bacteroidetes-Porphyromonas-Prevotella group, Bacteroidetes fragilis } \\
\text { subgroup, and Eubacterium rectale-Clostridium coccoides group, and increased } \\
\text { Lactobacillus. }\end{array}$ \\
Inflammatory bowel disease & $\begin{array}{l}\text { Dysbiotic inflammatory response to intestinal microbes. Increased numbers of } \\
\text { innate immunity cells (neutrophils, macrophages, dendritic cells, and natural killer } \\
\text { T cells) and adaptive immunity cells (B and T lymphocytes), which enact immune } \\
\text { tolerance or defense against the intestinal microbiota. } \\
\text { Irritable bowel syndrome }\end{array} \quad$ Enrichment of Firmicutes and reduction of Bacteroidetes.
\end{tabular}

Irritable bowel syndrome

Ulcerative colitis

Crohn's disease

Ileal Crohn's disease

Type 1 diabetes

Asthma

Obesity

Obesity and gastric bypass

Cancer (various)

Typhoid fever

Food poisoning and foodborne pathogens

Malnutrition

Clostridium difficile Infection

Peptic ulcer disease

Chronic gastritis

Gastric Mucosa-associated lymphoid tissue (MALT) tumors

Multiple sclerosis
Reduction of Bifidobacteria. Inflammation confined to the mucosa of the colon.

Reduction of Firmicutes and Bacteroidetes. Transmural inflammation.

A form of Crohn's disease typified by decreased Paneth cell $\alpha$-defensins, weakened antibacterial activity of the ileal mucosa, leading to bacterial composition changes in the microbiota.

Auto-immunity against pancreatic $\beta$-cells (normally producing insulin) in genetically predisposed individuals. Defective development or alterations of the microbiota may result in dysregulated immunity with autoimmune $\beta$-cells destruction, and/or increased leakiness of the gut epithelial barrier. Decreased microbiome diversity.

The airway microbiome is affected by outbreaks of Chlamydophila pneumoniae during the development of bronchitis and pneumonia. The Gl microbiota is affected by the environmental exposure of microbes, especially early in life, which in turn affects the maturation of immune function to protect against allergic sensitization. of the former, leading to obesity in conjunction with poor diet.

Significantly fewer Firmicutes compared to obese and healthy patients. Increase in Gammaproteobacteria in post-gastric-bypass patients. from infectious agents, genetic mechanism, or pathogens (e.g., Helicobacter pylori, Salmonella enterica, Borrelia burgdorferi, Chlamydia psittaci).

Caused by infection of Salmonella species (spp.) S. enterica serovar Typhi (S. Typhi).

Opportunistic pathogens (e.g., Campylobacter, Salmonella, E. coli, Shigella, Cronobacter, Listeria, Cryptosporidium, MRSA, etc.) disrupt the equilibrium of the microbiome leading to dysbiosis, loss of host bacterial diversity and multiple diseases.

Decrease or absence of species that either efficiently process food categories or produce vitamins may lead to reduced nutrient absorption and inflammation. Enterobacteriaceae overgrowth may result in epithelial damage, diarrhea, and reduced nutrient absorption.

A nosocomial pathogen, CDI is associated with epithelial inflammation and necrosis of the colon, diarrhea, pseudomembranous colitis and toxic megacolon. Antibiotic exposure may increase risk of re-infection.

Helicobacter pylori are $\mathrm{H}_{2}$ - receptor antagonists responsible for peptic ulcers, found in the stomach or duodenum. $H$. pylori was found to modify epithelial proliferation and apoptosis in gastric mucosa, reducing proliferation and increasing apoptosis in vitro in models of $H$. pylori infection.

$H$. pylori infection shown to increase epithelial cell turnover rate in gastric mucosa, with increased proliferation and apoptosis rates.

Associated with H. pylori infections. Microbial virulence factors (e.g., CagA, and VacA) activate inflammatory processes and cell proliferation.

Increased Methanobrevibacter (phylum Euryarchaeota) and Akkermansia (phylum Verrucomicrobia) and decreased Butyricimoas (phylum Bacteroidetes).
Shift in the proportion of Firmicutes and Bacteroidetes with a significant increase

Carcinogenesis may develop in response to epithelial injury and inflammation

\section{References}

Wu et al., 2016

Abraham and Cho, 2009; Halfvarson et al., 2016

Krogius-Kurikka et al., 2009; Rajilić-Stojanović et al., 2011; Jeffery et al., 2012; Kennedy et al., 2014

Abraham and Cho, 2009; Duranti et al., 2016

Eckburg and Relman, 2007; Abraham and Cho, 2009

Wehkamp et al., 2005

Atkinson and Eisenbarth, 2001; Bosi et al., 2006; Vaarala et al., 2008; Atkinson et al., 2013; Dunne et al., 2014

Hahn et al., 1991; Huang and Boushey, 2015

Consortium THMP, 2012; John and Mullin, 2016

Zhang et al., 2009

Virchow, 1863; Balkwill and Mantovani, 2001;

Grivennikov et al., 2010; Moore and Chang, 2010; Trinchieri, 2012; Schwabe and Jobin, 2013

Rabsch et al., 2001; Crump and Mintz, 2010;

Graham, 2010; Ahmer and Gunn, 2011

Brown et al., 2012; Shim, 2013; Carriere et al., 2015; Josephs-Spaulding et al., 2016

Mohan et al., 2006; Lupp et al., 2007; Round and Mazmanian, 2009; Kane et al., 2015

Heinlen and Ballard, 2010; Khanna et al., 2016

Ding et al., 2008; Prabhu and Shivani, 2014

Wagner et al., 1997; Ahmed et al., 2000; Jang and Kim, 2000; Choi et al., 2003; Suzuki et al., 2004; Ernst et al., 2006; Ding et al., 2008

Fox and Wang, 2007; Francescone et al., 2014; Wang et al., 2014

Jangi et al., 2015 
TABLE 1 | Continued

\begin{tabular}{|c|c|c|}
\hline Disease & Features & References \\
\hline Depression & $\begin{array}{l}\text { Bifidobacterium infantis, normally found in Gl of neonatal infants and in } \\
\text { administered probiotic drugs may have antidepressant effects in } \\
\text { psychobiological systems. }\end{array}$ & $\begin{array}{l}\text { Desbonnet et al., 2010; Dinan et al., 2013; Evrensel } \\
\text { and Ceylan, } 2015\end{array}$ \\
\hline Anxiety & $\begin{array}{l}\text { Oral administration of subclinical doses of Campylobacter jejuni in murine } \\
\text { models induced anxiety-like behavior without stimulating immunity. Lactobacillus } \\
\text { and Bifidiobacterium may function as anxiolytic influence in a murine model. }\end{array}$ & $\begin{array}{l}\text { Sudo, 2006; Lyte et al., 1998; Bravo et al., 2011; } \\
\text { Messaoudi et al., 2011; Barrett et al., 2012; } \\
\text { Evrensel and Ceylan, 2015; Akkasheh et al., 2016; } \\
\text { Schnorr and Bachner, } 2016\end{array}$ \\
\hline Non alcoholic fatty liver disease & Reduced levels of Bacteroidaceae, Bacteroides and Oscillospira & Chierico et al., 2016 \\
\hline Diarrheal illness & $\begin{array}{l}\text { Enteric infection of the jejunum caused by Cyclospora cayetanensis, a } \\
\text { foodborne and waterborne parasite. Results in diarrhea, including what is } \\
\text { referred to as traveler's diarrhea. }\end{array}$ & Ortega and Sanchez, 2010 \\
\hline Giardiasis & $\begin{array}{l}\text { Infection of the protozoan Giardia lamblia transmitted through the consumption } \\
\text { of contaminated drinking water inducing abdominal cramps, gas, nausea, and } \\
\text { weight loss. In a murine model, Giardia colonization and proliferation affected } \\
\text { commensal bacteria with decreased Firmicutes and Melainabacteria, and } \\
\text { increased Proteobacteria. }\end{array}$ & Maloney et al., 2015; Barash et al., 2017 \\
\hline
\end{tabular}

Invariant natural killer T cells (iNKT cells) are part of innate immunity and mediate inflammation via interleukins IL-4 and IL-2. In a murine asthma model, germ-free mice were found to have higher counts of iNKT cells, compared to specific pathogen free mice (Ferreira et al., 2014). In contrast, germfree mice colonized with normal mice microbiota appeared protected from the inflammatory effects of accumulated iNKT cells and from asthma (ib.). Interestingly, this was true only if gut colonization occurred in newborns, supporting the idea that early life microbial exposure may promote immune system proficiency and potentially offer disease protection later in life (Ferreira et al., 2014). Similarly, neonatal introduction of Lactobacillus rhamnosus GG, a probiotic strain of human origin, reduced allergic responses in the airways (ib.). L. rhamnosus was found to induce macrophages and to moderately activate the inflammasomes, cytoplasmic complexes responsible for the regulation of the pro-inflammatory response and induce macrophages (Martinon et al., 2009). Interestingly L. rhamnosus exposure was also found to cross-protect the mice from influenza A viral infection (Miettinen et al., 2012). Underscoring the complexity of host-microbe interactions, comparison of the global gene activation patterns elicited by the related $L$. rhamnosus GG and LC705 strains revealed that, despite their high degree of genetic relatedness, the two strains provoked distinct responses in the host and displayed different levels of gene activation with the induction of distinct gene sets (ib.).

\section{Inflammatory Bowel Disease}

Inflammatory bowel disease (IBD) is an aggravating longterm inflammation of the intestine in which the commensal microbiota plays a key role in conjunction with individual genetic susceptibility (Elson et al., 2005; Obermeier et al., 2005; Schirbel and Fiocchi, 2010; Ferreira et al., 2014; Liu et al., 2015). IBD patients suffer intermittent severe bowel inflammation and displayed distinct composition of the gut microbiota, with decreased Firmicutes (Table 1, Walker et al., 2010; Ferreira et al., 2014). Abnormal GI microbiota has also been observed in subsets of patients affected by Crohn's disease and ulcerative colitis, two IBD variants (Park et al., 2017). Compared to healthy controls, the GI microbiota of IBD patients displayed fewer bacteria with anti-inflammatory properties and/or more bacteria with pro-inflammatory properties (Ott, 2004; Ferreira et al., 2014; Park et al., 2017). Inflammasome activation in the gut triggered a cascade culminating in release of interleukins IL$1 \beta$ and IL-18, which in turn stimulated the inflammasome and amplified the inflammatory response (Miettinen et al., 2012). Corroborating a causal link between GI microbiota and $\mathrm{IBD}$, the resident bacteria in the GI tract were found to prevent or alleviate IBD in murine models (Ferreira et al., 2014). Germ-free mice were prone to developing colitis and Crohn's disease, while gut re-colonization following gavage with healthy microbiota decreased inflammation (ib.). Early observations indicated that IBD patients displayed damaged intestinal barrier and increased intestinal permeability allowing microbe translocation and activation of the systemic immunity (Hollander et al., 1986). Translocation is a mechanism by which microbes can break through the gut barrier, enter the circulation and may reach other organs, unless targeted by innate and adaptive immunity. Revealing a degree of functional overlap, the gut microbiota was found to prevent translocation of the probiotic E. coli strain Nissle 1917 even if either the adaptive or innate immune system were to be defective (Gronbach et al., 2010). Conversely, in the absence of a GI microbiota the host's immunity could prevent microbial translocation (ib.). IBD susceptibility appeared to be linked to multiple defects affecting the gut barrier, Paneth cells, and innate immunity that result in decreased tolerance and increased immune response (Jostins et al., 2012; Buttó et al., 2015; Liu et al., 2015). Changes in resident microbiota composition following antibiotic treatment or other stressors (e.g., inflammation, Lupp et al., 2007) may favor the proliferation of pathogens, such as $C$. difficile, Enterococcus, Salmonella, and Escherichia species (Keeney and Finlay, 2011; Ng et al., 2013) causing further dysbiosis. These bacteria were found to efficiently utilize the nutrients in the 
gut environment and, at least in the case of Salmonella, be able to simultaneously implement adhesion mechanisms and bacteriotoxin production to, respectively, resist the host immunity and outcompete the resident microbiota (Raffatellu et al., 2009; Winter et al., 2010). IBD patients may also suffer the outgrowth of opportunistic pathogens or pathobionts, as a result of their unbalanced microbiota. Unlike the pathogens described above, these species are normally found within the human GI microbiota, yet they are kept under control. The imbalance of dysbiosis however, may favor their proliferation and the expression and/or proliferation of their virulent traits. Among these pathobionts were identified species of Klebsiella, Proteus, and Escherichia (Darfeuille-Michaud et al., 2004; Baumgart et al., 2007; Lupp et al., 2007; Walters et al., 2014; Buttó et al., 2015).

Finally, the high levels of inflammation characterizing IBD likely affect the microbiota as they do the host, inducing molecular and physiological changes. It was found that in response to harsh environments $E$. coli-which is found enriched in IBD patients (Table 1) - could up-regulate the $i b p A$ and $i b p B$ genes belonging to the stress response regulon, which are involved in cell division, signal transduction and intestinal adhesion (Zuckert, 2014; Tao et al., 2015). In the IL10-/- IBD model mouse inoculated with a murine isolate of colitis-inducing E. coli (NC101), ibpA and $i b p B$ were found to be activated, presumably to cope with the high amounts of reactive oxygen species induced by intestinal inflammation and-possiblyby the increased temperature caused by inflammation (Patwa et al., 2011). Surprisingly, this response impaired E. coli luminal growth and decreased survival after macrophage phagocytosis, which seemed counter-intuitive (ib.). While these observations may be partially limited due to the use of a monoassociated mouse and the focus on luminal bacteria, they indicate that the microbiota is rapidly and dynamically responding to the host conditions.

\section{FECAL TRANSPLANTATION}

Recognizing that gut microbes are so integral to human health, the prospect of reconstituting a healthy microbiota in cases of dysbioses or disease becomes particularly attractive. Fecal microbiota transplantation (FMT) aims at reversing altered microbiota to their native state or one with healthy functionality. In FMT intestinal microbiota obtained from a healthy donor is processed, standardized and finally transplanted into the intestine of a recipient. FMT is being considered in alternative to antibiotic therapy to treat chronic $C$. difficile infections (CDI) that occur in dysbioses. The United States record over 500,000 annual cases of CDI, making it the leading cause of nosocomial diarrhea which, untreated, can result in lethal toxic megacolon (Bakken et al., 2011). Aggressive antibiotic therapies have produced chronic conditions with antibiotic resistant and hyper-virulent $C$. difficile strains overtaking a severely depleted GI microbiota (Cammarota et al., 2014; Khoruts, 2014). The current treatment for CDI is oral vancomycin administration, despite dwindling efficacies and a recorded $20-60 \%$ relapse within the first month following the completion of the course of vancomycin (Brandt et al., 2011). With limited options to eradicate $C$. difficile infections, FMT seems a viable alternative for restoring a healthy GI microbiota while avoiding the undesirable effects of antibiotics. CDI characteristic dysbiosis revealed dominating Gammaproteobacteria and Bacilli and rare Clostridia and Bacteroidetes, which were instead abundant in normal GI microbiota (Shankar et al., 2014). 16S rRNA profiling of the fecal bacteria following FMT showed apparent restoration of the microbial community and absence of $C$. difficile (Seekatz et al., 2014; Shankar et al., 2014). The decreased symptoms and clinical improvements remained stable for at least four months post procedure (Shankar et al., 2014), while FMT re-established a GI microbiota whose composition shifted from the diseased state and resembled more that of the donor (ib.). These landmark studies reported an impressive 90\% success rate in reducing the debilitating CDI symptoms in a small patient cohort. The enthusiasm was tempered by finding much rarer successes in severe CDI (Zainah et al., 2014), albeit the procedure appeared safe and successful in appropriately chosen patients (Chapman et al., 2016). Although the transplanted microbiota appeared to generate a healthier microbiota taxonomy and could resolve the CDI symptoms (Bakken, 2009; van Nood et al., 2013; Zainah et al., 2014), many aspects of FMT demand further analyses and larger clinical studies. A better definition of the composition(s) of healthy gut microbiota and further understanding of how FMT affects the GI microbial community, its physiological interactions with the patient and how long the changed microbiota is maintained in the patients will all contribute to the further development of this procedure (Bakken, 2009; Brandt, 2013; Cammarota et al., 2014; Colman and Rubin, 2014; Khoruts and Weingarden, 2014; Moayyedi et al., 2014; Zainah et al., 2014; Dai et al., 2015).

\section{CONCLUDING REMARKS}

Convincing accumulating evidence shows that the human gut microbiota contributes to many aspects of human health via molecular pathways that we only begin to understand. The GI microbiota entertains deep mutualistic relationships and coevolves with the human host, albeit at a much faster rate and demonstrates deep ecological links with the host which are being studied at the interface between Biology, Ecology, and Medicine. Experimental probing of the deep and reciprocal ties characterizing the microbiota-host relationship constitutes a formidable challenge, yet holds the promise to shed light on unknown aspects of human and microbial physiology and novel therapeutic possibilities in the manipulation of microbiota composition via antibiotics, probiotics, and microbial transplantation. Progress in microbiota studies and the recent discovery of the first new antibiotic in 30 years isolated from the pool of "un-culturable bacteria" (Ling et al., 2015) rekindle the hopes to find new therapeutics less prone to elicit microbial resistance. Because of the trophic relationships between host and gut microorganisms, dietary manipulation to supply appropriate nutrients favoring specific classes of 
beneficial microorganism may also aid future therapies for chronic pathologies displaying gut dysbiosis, such as asthma, IBD, and RA.

\section{AUTHOR CONTRIBUTIONS}

This manuscript is the result of collaborative work during the Microbiology course (BIOL371) at Concordia University. MA, HAk, HAl, $\mathrm{HBr}, \mathrm{ABa}, \mathrm{FB}, \mathrm{VB}, \mathrm{RB}, \mathrm{ABr}, \mathrm{MCa}, \mathrm{TC}, \mathrm{MCh}, \mathrm{EK}$, AS contributed text on microbial adhesion and colonization mechanisms; SE, CE, NFe, NFl, TF, MGa, MGe, SG, NG, JB, $\mathrm{TH}$ contributed text on bacterial competition and foreign species invasion; JC, KC, FC, SD, IH, MI, SI, SK, PL, KL contributed text on the microbiota interactions with the host's immune system; DJ, AJ, MJ, MK contributed text on microbiome alterations and human pathologies; KK, CK, HK contributed text on the gut brain axis; SL, JL, YM, PM, ML, EN, IN, TNg, RN, MO’D, $\mathrm{MOu}, \mathrm{VS}, \mathrm{TNa}, \mathrm{TU}$ contributed text on fecal transplant; YM, $\mathrm{PM}, \mathrm{TU}, \mathrm{VS}$ also contributed text on legal implications of the fecal transplants that allowed the development of the review in its current state, albeit it is not represented in the current manuscript; SP, NP, EP, JM contributed text on the emerging roles for the gut microbiome and new perspectives; JP, AP, CP, VP, $\mathrm{HR}, \mathrm{RR}, \mathrm{JR}, \mathrm{DR}$ contributed text on the relationships between diet and microbiome; BR, SSa, MS, SSe, LS, AS, DS, contributed text on the efficacy of supplementation and persistence of

\section{REFERENCES}

Abraham, C., and Cho, J. (2009). Inflammatory bowel diseases. N. Engl. J. Med. 15, 1090-1100. doi: 10.1056/nejmra0804647

Ahmed, A., Smoot, D., Littleton, G., Tackey, R., Walter, C. S., Kashanchi, F., et al. (2000). Helicobacter pylori inhibits gastric cell cycle progression. Microbes Infect. 2, 1159-1169. doi: 10.1016/S1286-4579(00)01270-3

Ahmer, B. M. M., and Gunn, J. S. (2011). Interaction of Salmonella spp. with the intestinal microbiota. Front. Microbiol. 2:101. doi: 10.3389/fmicb.2011.00101

Akkasheh, G., Kashani-Poor, Z., Tajabadi-Ebrahimi, M., Jafari, P., Akbari, H., Taghizadeh, M., et al. (2016). Clinical and metabolic response to probiotic administration in patients with major depressive disorder: a randomized, double-blind, placebo-controlled trial. Nutrition 32, 315-320. doi: 10.1016/j.nut.2015.09.003

Alcock, J., Maley, C. C., and Aktipis, C. A. (2014). Is eating behavior manipulated by the gastrointestinal microbiota? Evolutionary pressures and potential mechanisms. Bioessays 36, 940-949. doi: 10.1002/bies.201400071

Allan, K., and Devereux, G. (2011). Diet and asthma: nutrition implications from prevention to treatment. J. Am. Diet. Assoc. 111, 258-268. doi: 10.1016/j.jada.2010.10.048

Arumugam, M., Raes, J., Pelletier, E., Paslier, D. L., Yamada, T., Mende, D. R., et al. (2011). Addendum: enterotypes of the human gut microbiome. Nature 506, 516-516. doi: 10.1038/nature13075

Atkinson, M. A., and Eisenbarth, G. S. (2001). Type 1 diabetes: new perspectives on disease pathogenesis and treatment. Lancet 358, 221-229. doi: 10.1016/S0140-6736(01)05415-0

Atkinson, M. A., Eisenbarth, G. S., and Michels, A. W. (2013). Type 1 diabetes. Lancet 383, 69-82. doi: 10.1016/S0140-6736(13)60591-7

Avau, B., and Depoortere, I. (2015). The bitter truth about bitter taste receptors: beyond sensing bitter in the oral cavity. Acta Physiol. 216, 407-420. doi: 10.1111/apha.12621

Avau, B., Bauters, D., Steensels, S., Vancleef, V., Laermans, J., Lesuisse, J., et al. (2015). The gustatory signalling pathways and bitter taste receptors affect the development of obesity and adipocyte metabolism in mice. PLoS ONE 10:e0145538. doi: 10.1371/journal.pone. 0145538 probiotic strains; MVa, MVi contributed text on microbiota and fasting; PV, LW, CZ, PdS, MW contributed text on commensal microorganisms and cancer; AA, TA, LA, IB contributed text on anti-microbial peptides; $\mathrm{HBe}, \mathrm{MDa}, \mathrm{MDe}, \mathrm{TD}, \mathrm{SDi}, \mathrm{SDo}, \mathrm{PD}$, FD, LD contributed text on antibiotics and antibiotic resistance that was excluded in part from the text of the revised document, yet contributed to the article in its final format. In addition, SSe and BR collaborated to fuse all individual contributions into a cohesive manuscript; CG conceived, organized, and edited the manuscript. All authors read and approved the final manuscript.

\section{FUNDING}

This manuscript was curated as an educational project on a volunteer basis from each and all authors, including the corresponding, and no funding was utilized.

\section{ACKNOWLEDGMENTS}

Special thanks go to Concordia University Biology Librarian Katharine Hall for her help and support throughout the realization of this project. We would also like to thank Dr. D. Quaglia for comments on the manuscript and Professors W. D. Lubell and P. Gulick for their encouragement and discussion.
Bäckhed, F., Ding, H., Wang, T., Hooper, L. V., Koh, G. Y., Nagy, A., et al. (2004). The gut microbiota as an environmental factor that regulates fat storage. Proc. Natl. Acad. Sci. U.S.A. 101, 15718-15723. doi: 10.1073/pnas.0407076101

Bäckhed, F., Ley, R. E., Sonnenburg, J. L., Peterson, D. A., and Gordon, J. I. (2005). Host-bacterial mutualism in the human intestine. Science 307, 1915-1920. doi: 10.1126/science.1104816

Bakken, J. S. (2009). Fecal bacteriotherapy for recurrent clostridium difficile infection. Anaerobe 15, 285-289. doi: 10.1016/j.anaerobe.2009.09.007

Bakken, J. S., Borody, T., Brandt, L. J., Brill, J. V., Demarco, D. C., Franzos, M. A., et al. (2011). Treating Clostridium difficile infection with fecal microbiota transplantation. Clin. Gastroenterol. Hepatol. 9, 1044-1049. doi: 10.1016/j.cgh.2011.08.014

Balkwill, F., and Mantovani, A. (2001). Inflammation and cancer: back to Virchow? Lancet 357, 539-545. doi: 10.1016/S0140-6736(00)04046-0

Barash, N. R., Maloney, J. G., Singer, S. M., and Dawson, S. C. (2017). Giardia alters commensal microbial diversity throughout the murine gut. Infect. Immun. 85:e00948-16. doi: 10.1128/iai.00948-16

Barrett, E., Ross, R. P., Toole, P. W. O., Fitzgerald, G. F., and Stanton, C. (2012). $\gamma$-Aminobutyric acid production by culturable bacteria from the human intestine. J. Appl. Microbiol. 113, 411-417. doi: 10.1111/j.1365-2672.2012.05344.x

Barroso-Batista, J., Sousa, A., Lourenço, M., Bergman, M. L., Sobral, D., Demengeot, J., et al. (2014). The first steps of adaptation of Escherichia coli to the gut are dominated by soft sweeps. PLoS Genet. 10:e1004182. doi: 10.1371/journal.pgen.1004182

Baumgart, M., Dogan, B., Rishniw, M., Weitzman, G., Bosworth, B., Yantiss, R., et al. (2007). Culture independent analysis of ileal mucosa reveals a selective increase in invasive Escherichia coli of novel phylogeny relative to depletion of Clostridiales in Crohn's disease involving the ileum. ISME J. 1, 403-418. doi: 10.1038/ismej.2007.52

Becker, N., Kunath, J., Loh, G., and Blaut, M. (2011). Human intestinal microbiota: characterization of a simplified and stable gnotobiotic rat model. Gut Microbes. 2, 25-33. doi: 10.4161/gmic.2.1.14651

Belenguer, A., Duncan, S. H., Calder, A. G., Louis, P., Lobley, G. E., and Flint, H. J. (2006). Two rotes of metabolic cross-feeding between Bifidobacterium 
adolescentis and butyrate-producing anaerobes from the human gut. Appl. Environ. Microbiol. 2, 3593-3599. doi: 10.1128/AEM.72.5.3593-3599.2006

Belkaid, Y., and Harrison, O. J. (2017). Homeostatic immunity and the microbiota. Immunity 46, 562-576. doi: 10.1016/j.immuni.2017.04.008

Bercik, P., Collins, S. M., and Verdu, E. F. (2012). Microbes and the gut-brain axis. Neurogastroent Motil. 24, 405-413. doi: 10.1111/j.1365-2982.2012.01906.x

Bergstrom, A., Skov, T. H., Bahl, M. I., Roager, H. M., Christensen, L. B., Ejlerskov, K. T., et al. (2014). Establishment of intestinal microbiota during early life: a longitudinal, explorative study of a large cohort of danish infants. Appl. Environ. Microbiol. 80, 2889-2900. doi: 10.1128/AEM.00342-14

Berry, D. (2016). The emerging view of Firmicutes as key fibre degraders in the human gut. Environ. Microbiol. 18, 2081-2083. doi: 10.1111/1462-2920.13225

Bjursell, M. K., Martens, E. C., and Gordon, J. I. (2006). Functional genomic and metabolic studies of the adaptations of a prominent adult human gut symbiont, Bacteroides thetaiotaomicron, to the suckling period. J. Biol. Chem. 281, 36269-36279. doi: 10.1074/jbc.M606509200

Booth, A. (2014). Symbiosis, selection, and individuality. Biol. Philos. 29, 657-673. doi: $10.1007 /$ s10539-014-9449-8

Bordenstein, S. R., and Theis, K. R. (2015). Host biology in light of the microbiome: ten principles of holobionts and hologenomes. PLoS Biol. 13:e1002226. doi: 10.1371/journal.pbio.1002226

Bosi, E., Molteni, L., Radaelli, M. G., Folini, L., Fermo, I., and Bazzigaluppi, E., et al. (2006). Increased intestinal permeability precedes clinical onset of type 1 diabetes. Diabetologia 49, 2824-2827. doi: 10.1007/s00125-006-0465-3

Bouhnik, Y., Raskine, L., Simoneau, G., Paineau, D., and Bornet, F. (2006). The capacity of short-chain fructo-oligosaccharide to stimulate fecal bifidobacteria: a dose-response relationship study in healthy humans. Nutrition 5:8. doi: 10.1186/1475-2891-5-8

Bouhnik, Y., Raskine, L., Simoneau, G., Vicaut, E., Neut, C., Flourie, B., et al. (2004). The capacity of nondigestible carbohydrates to stimulate fecal bifidobacterium in healthy humans: a double-blind, randomized, placebocontrolled, parallel-group, dose-response relation study. Am. J. Clin. Nutr. 80, 1658-1664.

Brandt, L. J. (2013). FMT: first step in a long journey. Am. J. Gastroenterol. 108, 1367-1368. doi: 10.1038/ajg.2013.165

Brandt, L. J., Borody, T. J., and Campbell, J. (2011). Endoscopic fecal microbiota transplantation. J. Clin. Gastroenterol. 45, 655-657. doi: 10.1097/MCG.0b013e3182257d4f

Brandtzaeg, P., Carlsen, H. S., and Halstensen, T. S. (2006). The B-cell system in inflammatory bowel disease. Adv. Exp. Med. Biol. 579, 149-167. doi: 10.1007/0-387-33778-4_10

Bravo, J. A., Forsythe, P., Chew, M. V., Escaravage, E., Savignac, H. M., Dinan, T. G., et al. (2011). Ingestion of Lactobacillus strain regulates emotional behavior and central GABA receptor expression in a mouse via the vagus nerve. Proc. Natl. Acad. Sci. U.S.A. 108, 16050-16055. doi: 10.1073/pnas.1102999108

Brown, K., DeCoffe, D., Molcan, E., and Gibson, D. L. (2012). Diet-induced dysbiosis of the intestinal microbiota and the effects on immunity and disease. Nutrients 4, 1095-1119. doi: 10.3390/nu4081095

Browne, H. P., Forster, S. C., Anonye, B. O., Kumar, N., Neville, B. A., Stares, M. D., et al. (2016). Culturing of 'unculturable' human microbiota reveals novel taxa and extensive sporulation. Nature 533, 543-546. doi: 10.1038/nature 17645

Buttó, L. F., Schaubeck, M., and Haller, D. (2015). Mechanisms of microbehost interaction in Crohn's disease: dysbiosis vs. pathobiont selection. Front. Immunol. 6:555. doi: 10.3389/fimmu.2015.00555

Butto, L. F., and Haller, D. (2016). Dysbiosis in intestinal inflammation cause or consequence. Med. Microbiol. 306, 302-309. doi: 10.1016/j.ijmm.2016.02.010

Cammarota, G., Ianiro, G., Bibbò, S., and Gasbarrini, A. (2014). Gut microbiota modulation: probiotics, antibiotics or fecal microbiota transplantation? Intern. Emerg. Med. 9, 365-373. doi: 10.1007/s11739-014-1069-4

Carriere, J., Bretin, A., Barnich, N., and Nguyen, H. T. T. (2015). Crohn's diseaseassociated adherent-invasive Escherichia coli induce secretion of exosomes with pro-inflammatory activity by intestinal epithelial cells. Gastroenterology 148:S710. doi: 10.1016/S0016-5085(15)32411-2

Chapman, B. C., Moore, H. B., Overbey, D. M., Morton, A. P., Harnke, B., Gerich, M. E., et al. (2016). Fecal microbiota transplant in patients with Clostridium difficile infection. J. Trauma Acute Care Surg. 81, 756-764. doi: 10.1097/TA.0000000000001195

Chelvam, K. K., Chai, L., and Thong, K. (2014). Variations in motility and biofilm formation of Salmonella enterica serovar Typhi. Gut Pathog. 6:2. doi: $10.1186 / 1757-4749-6-2$
Chierico, F. D., Nobili, V., Vernocchi, P., Russo, A., De Stefanis, S., Gnani, D., et al. (2016). Gt microbiota profiling of pediatric nonalcoholic fatty liver disease and obese patients unveiled by an integrated meta-omics based approach. Hepatology 65, 451-464. doi: 10.1002/hep. 28572

Cho, I., and Blaser, M. J. (2012). The human microbiome: at the interface of health and disease. Nat. Rev. Genet. 13, 260-270. doi: 10.1038/nrg3182

Choi, I. J., Kim, J. S., Kim, J. M., Jung, H. C., and Song, I. S. (2003). Effect of inhibition of extracellular signal-regulated kinase 1 and 2 pathway on apoptosis and bcl-2 expression in Helicobacter pylori-infected AGS cells. Infect. Immun. 71, 830-837. doi: 10.1128/IAI.71.2.830-837.2003

Chung, H., Pamp, S. J., Hill, J. A., Surana, N. K., Edelman, S. M., Troy, E. B., et al. (2012). Gut immune maturation depends on colonization with a host-specific microbiota. Cell 149, 1578-1593. doi: 10.1016/j.cell.2012.04.037

Clarke, G., Stilling, R. M., Kennedy, P. J., Stanton, C., Cryan, J. F., and Dinan, T. G. (2014). Gut microbiota: the neglected endocrine organ. Mol. Endocrinol. 28, 1221-1238. doi: 10.1210/me.2014-1108

Collins, S. M., Surette, M., and Bercik, P. (2012). The interplay between the intestinal microbiota and the brain. Nat. Rev. Microbiol. 10, 735-742. doi: $10.1038 /$ nrmicro2876

Colman, R. J., and Rubin, D. T. (2014). Fecal microbiota transplantation as therapy for inflammatory bowel disease: a systematic review and meta-analysis. J. Crohn's Colitis 8, 1569-1581. doi: 10.1016/j.crohns.2014.08.006

Conlon, M., and Bird, A. (2014). The impact of diet and lifestyle on gut microbiota and human health. Nutrients 7, 17-44. doi: 10.3390/nu7010017

Consortium THMP (2012). Structure, function and diversity of the healthy human microbiome. Nature 486, 207-214. doi: 10.1038/nature11234

Corr, S. C., Li, Y., Riedel, C. U., O’toole, P. W., Hill, C., and Gahan, C. G. M. (2007). Bacteriocin production as a mechanism for the antiinfective activity of Lactobacillus salivarius UCC118. Proc. Natl. Acade. Sci. U.S.A. 104, 7617-7621. doi: 10.1073/pnas.0700440104

Crump, J. A., and Mintz, E. D. (2010). Global trends in typhoid and paratyphoid fever. Clin. Infect. Dis. 50, 241-246. doi: 10.1086/649541

Cummings, J. H., Gibson, G. R., and MacFarlane, G. T. (1989). Quantitative estimates of fermentation in the hind gut of man. Acta Vet. Scand. 86, 76-82.

Cummings, J., and MacFarlane, G. (1997). Role of intestinal bacteria in nutrient metabolism. Clin. Nutr. 16, 3-11. doi: 10.1016/S0261-5614(97)80252-X

Dai, C., Jiang, M., and Sun, M.-J. (2015). Fecal microbiota transplantation for treatment of Clostridium difficile infection. J. Clin. Gastroenterol. 49, 171-172. doi: 10.1097/MCG.0000000000000189

Dalmasso, G., Nguyen, H. T. T., Yan, Y., Laroui, H., Charina, M. A., Ayyadurau, S., et al. (2011). Microbiota modulate host gene expression via MicroRNAs. PLoS ONE 6:e19293. doi: 10.1371/journal.pone.0019293

Darfeuille-Michaud, A., Boudeau, J., Bulois, P., Neut, C., Glasser, A. L., Barnich, N., et al. (2004). High prevalence of adherent-invasive Escherichia coli associated with ileal mucosa in Crohn's disease. Gastroenterology 127, 412-421. doi: 10.1053/j.gastro.2004.04.061

David, L. A., Maurice, C. F., Carmody, R. N., Gootenberg, D. B., Button, J. E., Wolfe, B. E., et al. (2014). Diet rapidly and reproducibly alters the human gut microbiome. Nature 505, 559-563. doi: 10.1038/nature12820

Davis, L. M., Martinez, I., Walter, J., Goin, C., and Hutkins, R. W. (2011). Barcoded pyrosequencing reveals that consumption of galactooligosaccharides results in a highly specific bifidogenic response in humans. PLoS ONE 6:e25200. doi: 10.1371/journal.pone.0025200

De Filippo, C., Cavalieri, D., Di Paola, M., Ramazzotti, M., Poullet, J. B., Massart, S., et al. (2010). Impact of diet in shaping gut microbiota revealed by a comparitive study in children from Europe and rural Africa. Proc. Natl. Acad. Sci. U.S.A. 107, 14691-14696. doi: 10.1073/pnas.1005963107

Degnan, P. H., Barry, N. A., Mok, K. C., Taga, M. E., and Goodman, A. L. (2014). Human gut microbes use multiple transporters to distinguish vitamin b12 analogs and compete in the gut. Cell Host Microbe 15, 47-57. doi: 10.1016/j.chom.2013.12.007

de la Serre, C. B., De Lartigue, G., and Raybould, H. E. (2015). Chronic exposure to Low dose bacterial lipopolysaccharide inhibits leptin signaling in vagal afferent neurons. Physiol. Behav. 139, 188-194. doi: 10.1016/j.physbeh.2014.10.032

de Muinck, E. J., Stenseth, N. C., Sachse, D., Roost, J. V., Rønningen, K. S., Rudi, K., et al. (2013). Context-dependent competition in a model gut bacterial community. PLoS ONE 8:e67210. doi: 10.1371/journal.pone. 0067210

Desbonnet, L., Garrett, L., Clarke, G., Kiely, B., Cryan, J. F., and Dinan, T. G. (2010). Effects of the probiotic Bifidobacterium infantis in the 
maternal separation model of depression. Neuroscience 170, 1179-1188. doi: 10.1016/j.neuroscience.2010.08.005

Dewar, M. L., Arnould, J. P. Y., Krause, L., Trathan, P., Dann, P., and Smith, S. C. (2014). Influence of fasting during moult on the fecal microbiota of penguins. PLoS ONE 9:e99996. doi: 10.1371/journal.pone.0099996

Dewulf, E. M., Cani, P. D., Claus, S. P., Fuentes, S., Puylaert, P. G., and Neyrinck, A. M., et al. (2013). Insight into the prebiotic concept: lessons from an exploratory, double blind intervention study with inulin-type fructans in obese women. Gut 62, 1112-11121. doi: 10.1136/gutjnl-2012-303304

Dill-Mcfarland, K. A., Neil, K. L., Zeng, A., Sprenger, R. J., Kurtz, C. C., Suen, G., et al. (2014). Hibernation alters the diversity and composition of mucosaassociated bacteria while enhancing antimicrobial defense in the gut of 13-lined ground squirrels. Mol. Ecol. 23, 4658-4669. doi: 10.1111/mec.12884

Dinan, T. G., Stanton, C., and Cryan, J. F. (2013). Psychobiotics: a novel class of psychotropic. Biol. Psychiatry 74, 720-726. doi: 10.1016/j.biopsych.2013.05.001

Ding, S. Z., Smith, M. F. J., and Goldberg, J. B. (2008). Helicobacter pylori and mitogen-activated protein kinases regulate the cell cycle, proliferation and apoptosis in gastric epithelial cells. J. Gastroenterol. Hepatol. 23(7 Pt 2), e67-e78. doi: 10.1111/j.1440-1746.2007.04912.x

Dobson, A., Cotter, P. D., Ross, R. P., and Hill, C. (2012). Bacteriocin production: a probiotic trait? Appl. Environ. Microbiol. 78, 1-6. doi: 10.1128/AEM.05576-11

Douglas, A. E., and Werren, J. H. (2016). Holes in the hologenome: why host-microbe symbiosis are not holobionts. MBio 7:e02099. doi: $10.1128 / \mathrm{mBio} .02099-15$

Du, Z., Hudcovic, T., Mrazek, J., Kozakova, H., Srutkova, D., Schwarzer, M., et al. (2015). Development of gut inflammation in mice colonized with mucosaassociated bacteria from patients with ulcerative colitis. Gut Pathog. 7:32. doi: 10.1186/s13099-015-0080-2

Dunne, J. L., Triplett, E. W., Gevers, D., Xavier, R., Insel, R., Danska, J., et al. (2014). The intestinal microbiome in type 1 diabetes. Clin. Exp. Immunol. 177, 30-37. doi: $10.1111 /$ cei.12321

Duranti, S., Gaiani, F., Mancabelli, L., Milani, C., Grandi, A., and Bolchi, A., et al. (2016). Elucidating the gut microbiome of ulcerative colitis: bifidobacteria as novel microbial biomarkers. FEMS Microbiol. Ecol. 92:fiw191. doi: 10.1093/femsec/fiw191

Eckburg, P. B., and Relman, D. A. (2007). The role of microbes in Crohn's disease. Clin. Infect. Dis. 44, 256-262. doi: 10.1086/510385

Ege, M. J., Mayer, M., Normand, A.-C., Genuneit, J., Cookson, W. O., BraunFahrländer, C., et al. (2011). Exposure to environmental microorganisms and childhood asthma. N. Engl. J. Med. 364, 701-709. doi: 10.1056/NEJMoa1007302

Ege, M. J., Mayer, M., Schwaiger, K., Mattes, J., Pershagen, G., Hage, M. V., et al. (2012). Environmental bacteria and childhood asthma. Allergy 67, 1565-1571. doi: $10.1111 /$ all.12028

Elson, C. O., Cong, Y., McCracken, V. J., Dimmitt, R. A., Lorenz, R. G., and Weaver, C. T. (2005). Experimental models of inflammatory bowel disease reveal innate, adaptive, and regulatory mechanisms of host dialogue with the microbiota. Immunol. Rev. 206, 260-276. doi: 10.1111/j.0105-2896.2005.00291.x

Ernst, P. B., Peura, D. A., and Crowe, S. E. (2006). The translation of Helicobacter pylori basic research to patient care. Gastroenterology 130, 188-206. quiz: 212-213. doi: 10.1053/j.gastro.2005.06.032

Eun, C. S., Mishima, Y., Wohlgemuth, S., Liu, B., Bower, M., Carroll, I. M., et al. (2014). Induction of bacterial antigen-specific colitis by a simplified human microbiota consortium in gnotobiotic interleukin-10-/- mice. Infect. Immun. 82, 2239-2246. doi: 10.1128/IAI.01513-13

Evans, C. C., Lepard, K. J., Kwak, J. W., Stancukas, M. C., Laskowski, S., Dougherty, J., et al. (2014). Exercise prevents weight gain and alters the gut microbiota in a mouse model of high fat diet-induced obesity. PLoS ONE 9:e92193. doi: 10.1371/journal.pone.0092193

Evans, D. F., Pye, G., Bramley, R., Clark, A. G., Dyson, T. J., and Hardcastle, J. D. (1988). Measurement of gastrointestinal $\mathrm{pH}$ profiles in normal ambulant human subjects. Gut 29, 1035-1041. doi: 10.1136/gut.29.8.1035

Evrensel, A., and Ceylan, M. E. (2015). The gut-brain axis: the missing link in depression. Clin. Psychopharmacol. Neurosci. 13, 239-244. doi: 10.9758/cpn.2015.13.3.239

Faith, J. J., Guruge, J. L., Charbonneau, M., Subramanian, S., Seedorf, H., Goodman, A. L., et al. (2013). The long-term stability of the human gut microbiota. Science 341:1237439. doi: 10.1126/science.1237439

Faust, K., Lahti, L., Gonze, D., de Vos, W. M., and Raes, J. (2015). Metagenomic meets time series analysis: unraveling microbial community dynamics. J. Curr. Opin. Microbiol. 25, 56-66. doi: 10.1016/j.mib.2015.04.004
Ferreira, C. M., Vieira, A. T., Vinolo, M. A. R., Oliveira, F. A., Curi, R., and Martins, F. D. S. (2014). The central role of the gut microbiota in chronic inflammatory diseases. J. Immunol. Res. 2014, 1-12. doi: 10.1155/2014/689492

Fischbach, M. A., and Sonnenburg, J. L. (2011). Eating for two: how metabolism establishes interspecies interactions in the gut. Cell Host Microbe 10, 336-347. doi: 10.1016/j.chom.2011.10.002

Flint, H. J., Bayer, E. A., Rincon, M. T., Lamed, R., and White, B. A. (2008). Polysaccharide utilization by gut bacteria: potential for new insights from genomic analysis. Nat. Rev. Microbiol. 6, 121-131. doi: 10.1038/nrmicro1817

Flint, H. J., Duncan, S. H., Scott, K. P., and Louis, P. (2014). Links between diet, gut microbiota composition and gut metabolism. Proc. Nutr. Soc. Proc. 74, 13-22. doi: 10.1017/S0029665114001463

Fox, J. G., and Wang, T. C. (2007). Inflammation, atrophy, and gastric cancer. J. Clin. Invest. 117, 60-69. doi: 10.1172/JCI30111

Francescone, R., Hou, V., and Grivennikoc, A. I. (2014). Microbiome, inflammation and cancer. Cancer J. 20, 181-189. doi: 10.1097/PPO.0000000000000048

Gerritsen, J., Smidt, H., Rijkers, G. T., and de Vos, W. M. (2011). Intestinal microbiota in human health and disease: the impact of probiotics. Genes Nutr. Genes 6, 209-240. doi: 10.1007/s12263-011-0229-7

Ghosh, S., Dai, C., Brown, K., Rajendiran, E., Makarenko, S., Baker, J., et al. (2011). Colonic microbiota alters host susceptibility to infectious colitis by modulating inflammation, redox status, and ion transporter gene expression. Amer. J. Physiol. Gastroenterol. Liver Physiol. 301, G39-G49. doi: 10.1152/ajpgi.00509.2010

Gilbert, S. F., Sapp, J., and Tauber, A. I. (2012). A symbiotic view of life: we have never been individuals. Q. Rev. Biol. 87, 325-341. doi: 10.1086/668166

Gill, S. R., Pop, M., Deboy, R. T., Eckburg, P. B., Turnbaugh, P. J., Samuel, B. S., et al. (2006). Metagenomic analysis of the human distal gut microbiome. Science 312, 1355-1359. doi: 10.1126/science.1124234

Giraud, A., Arous, S., De Paepe, M., Gaboriau-Routhiau, V., Bambou, J. C., Rakotobe, S., et al. (2008). Dissecting the genetic components of adaptation of escherichia coli to the mouse gut. PLoS Genet. 4:e2. doi: 10.1371/journal.pgen.0040002

Goto, Y., Obata, T., Kunisawa, J., Sato, S., Ivanov, I. I., Lamichhane, A., et al. (2014). Innate lymphoid cells regulate intestinal epithelial cell glycosylation. Science 345, 1254009-1254009. doi: 10.1126/science.1254009

Graham, S. M. (2010). Nontyphoidal salmonellosis in Africa. Curr. Opin. Infect. Dis. 23, 409-414. doi: 10.1097/QCO.0b013e32833dd25d

Griffin, N. W., Ahern, P. P., Cheng, J., Heath, A. C., Ilkayeva, O., Newgard, C. B., et al. (2017). Prior dietary practises and connections to a human gut microbial metacomminity alter responses to diet interventions. Host Microbe 21, 84-96. doi: 10.1016/j.chom.2016.12.006

Grivennikov, S. I., Greten, F. R., and Karin, M. (2010). Immunity, inflammation, and cancer. Cell 140, 883-899. doi: 10.1016/j.cell.2010.01.025

Gronbach, K., Eberle, U., Muller, M., Olschlager, T. A., Dobrindt, U., Leithauser, F., et al. (2010). Safety of probiotic Escherichia coli strain nissle 1917 depends on intestinal microbiota and adaptive immunity of the host. Infect. Immun. 78, 3036-3046. doi: 10.1128/IAI.00218-10

Guarner, F., and Malagelada, J.-R. (2003). Gut flora in health and disease. Lancet 361, 512-519. doi: 10.1016/S0140-6736(03)12489-0

Guinane, C. M., Tadrous, A., Fouhy, F., Ryan, C. A., Dempsey, E. M., Murphy, B., et al. (2013). Microbial composition of human appendices from patients following appendectomy. mBio 4:e00366-12. doi: $10.1128 / \mathrm{mBio}$. 00366-12

Hahn, D. L., Dodge, R. W., and Golubjatnikov, R. (1991). Association of Chlamydia pneumoniae (strain TWAR) infection with wheezing, asthmatic bronchitis, and adult-onset asthma. JAMA 266, 225-230. doi: 10.1001/jama.1991.03470020051031

Halfvarson, J., Brislawn, C. J., Lamendella, R., Vázquez-Baeza, Y., Walters, W. A., Bramer, L. M., et al. (2016). Dynamics of the human gut microbiome in inflammatory bowel disease. Nat. Microbiol. 2:17004. doi: 10.1038/nmicrobiol.2017.4

Heinlen, L., and Ballard, J. D. (2010). Clodridium difficile infection. Am. J. Med. Sci. 340, 247-252. doi: 10.1097/MAJ.0b013e3181e939d8

Hibbing, M. E., Fuqua, C., Parsek, M. R., and Peterson, S. B. (2010). Bacterial competition: surviving and thriving in the microbial jungle. Nat. Rev. Microbiol. 8, 15-25. doi: 10.1038/nrmicro2259

HMPC (2012a). Structure, function and diversity of the healthy human microbiome. Nature 486, 207-214. doi: 10.1038/nature11234 
HMPC (2012b). A framework for human microbiome research. Nature 486, 215-221. doi: 10.1038/nature11209

Hoffmann, C., Dollive, S., Grunberg, S., Chen, J., Li, H., Wu, G. D., et al. (2013). Archaea and fungi of the human gut microbiome: correlations with diet and bacterial residents. PLoS ONE 8:e66019. doi: 10.1371/journal.pone.0066019

Hold, G., Pryde, S. E., Russell, V. J., Furrie, E., and Flint, H. J. (2002). Assessment of microbial diversity in human colonic samples by $16 \mathrm{~S}$ rDNA sequence analysis. FEMS Microbiol. Ecol. 39, 33-39. doi: 10.1111/j.1574-6941.2002.tb00904.x

Hollander, D., Vadheim, C. M., Brettholz, E., Petersen, G. M., Delahunty, T., and Rotter, J. I. (1986). Increased intestinal permeability in patients with Crohn's disease and their relatives. A possible etiologic factor. Ann. Intern. Med. 105, 883-885. doi: 10.7326/0003-4819-105-6-883

Huang, J., and Boushey, H. A. (2015). The microbiome in asthma. J. Allergy Clin. Immunol. 135, 25-30. doi: 10.1016/j.jaci.2014.11.011

Huffnagle, G. B., and Noverr, M. C. (2013). The emerging world of the fungal microbiome. Trends Microbiol. 21, 334-341. doi: 10.1016/j.tim.2013.04.002

Hugon, P., Dufour, J. C., Colson, P., Fournier, P. E., Sallah, K., and Raoult, D. (2015). A comprehensive repertoire of prokaryotic species identified in human beings. Lancet Infect. Dis. 15, 1211-1219. doi: 10.1016/S1473-3099(15)00293-5

Hurd, E. A., and Domino, S. E. (2004). Increased susceptibility of secretor factor Fut2-null mice to experimental vaginal candidiasis. Infect. Immun. 72, 4279-4281. doi: 10.1128/IAI.72.7.4279-4281.2004

Iversen, H., Lindbäck, T., L'Abée-Lund, T. M., Roos, N., Aspholm, M., and Arnesen, L. S. (2015). The gut bacterium bacteroides thetaiotaomicron influences the virulence potential of the enterohemorrhagic Escherichia coli O103:H25. PLoS ONE 10:e0118140. doi: 10.1371/journal.pone.0118140

Jang, T. J., and Kim, J. R. (2000). Proliferation and apoptosis in gastric antral epithelial cells of patients infected with Helicobacter pylori. J. Gastroenterol. 35, 265-271. doi: 10.1007/s005350050344

Jangi, S., Gandhi, R., Cox, L. M., Li, N., Glehn, F. V., Yan, R., et al. (2015). Alterations of the human gut microbiome in multiple sclerosis. Nat. Commun. 7:12015. doi: 10.1038/ncomms 12015

Jeffery, I. B., O’Toole, P. W., Öhman, L., Claesson, M. J., Deane, J., Quigley, E. M., et al. (2012). An irritable bowel syndrome subtype defined by species-specific alterations in fecal microbiota. Gut 61, 997-1006. doi: 10.1136/gutjnl-2011-301501.

Johansen, F. E., Pekna, M., Norderhaug, I. N., Haneberg, B., Hietala, M. A., et al. (1999). Absence of epithelial immunoglobulin A transport, with increased mucosal leakiness, in polymeric immunoglobulin receptor/secretory component-deficient mice. J. Exp. Med. 190, 915-922. doi: 10.1084/jem.190.7.915

John, G. K., and Mullin, G. E. (2016). The gut microbiome and obesity. Curr. Oncol. Rep. 18, 45. doi: 10.1007/s11912-016-0528-7

Josephs-Spaulding, J., Beeler, E., and Singh, O. V. (2016). Human microbiome versus food-borne pathogens: friend or foe. Appl. Microbiol. Biotechnol. 100, 4845-4863. doi: 10.1007/s00253-016-7523-7

Jostins, L., Ripke, S., Weersma, R. K., Duerr, R. H., McGovern, D. P., Hui, K. Y., et al. (2012). Host-microbe interactions have shaped the genetic architecture of inflammatory bowel disease. Nature 491, 119-124. doi: 10.1038/nature11582

Kadooka, Y., Sato, M., Imaizumi, K., Ogawa, A., Ikuyama, K., Akai, Y., et al. (2010). Regulation of abdominal adiposity by probiotics (Lactobacillus gasseri SBT2055) in adults with obese tendencies in a randomized controlled trial. Eur. J. Clin. Nutr. 64, 636-643. doi: 10.1038/ejcn.2010.19

Kalliomäki, M., Kirjavainen, P., Eerola, E., Kero, P., Salminen, S., and Isolauri, E. (2001a). Distinct patterns of neonatal gut microflora in infants in whom atopy was and was not developing. J. Allergy Clin. Immunol. 107, 129-134. doi: $10.1067 /$ mai.2001.111237

Kalliomäki, M., Salminen, S., Arvilommi, H., Kero, P., Koskinen, P., and Isolauri, E. (2001b). Probiotics in primary prevention of atopic disease: a randomised placebo-controlled trial. Lancet 357, 1076-1079. doi: 10.1016/S0140-6736(00)04259-8

Kandori, H., Hirayama, K., Takeda, M., and Doi, K. (1996). Histochemical, lectin-histochemical and morphometrical characteristics of intestinal goblet cells of germfree and conventional mice. Exp. Anim. 45, 155-160. doi: 10.1538/expanim.45.155

Kane, A. V., Dinh, D. M., and Ward, H. D. (2015). Childhood malnutrition and the intestinal microbiome malnutrition and the microbiome. Pediatr. Res. 77, 256-262. doi: 10.1038/pr.2014.179
Keeney, K. M., and Finlay, B. (2011). Enteric pathogen exploitation of the microbiota-generated nutrient environment of the gut. Curr. Opin. Mibcrobiol. 14, 92-98. doi: 10.1016/j.mib.2010.12.012

Keeney, K. M., Yurist-Doutsch, S., Arrieta, M.-C., and Finlay, B. B. (2014). Effects of antibiotics on human microbiota and subsequent disease. Annu. Rev. Microbiol. 68, 217-235. doi: 10.1146/annurev-micro-091313-103456

Kennedy, P. J., Cryan, J. F., Dinan, T. G., and Clarke, G. (2014). Irritable bowel syndrome: a microbiome-gut-brain axis disorder? World J. Gatroenterol. 20, 14105-14125. doi: 10.3748/wjg.v20.i39.14105

Khanna, S., Pardi, D. S., Kelly, C. R., Kraft, C. S., Dhere, T., and Henn, M. R., et al. (2016). A novel microbiome therapeutic increases gut microbial diversity and prevents recurrentclostridium difficileinfection. J. Infect. Dis. 214, 173-181. doi: 10.1093/infdis/jiv766

Khoruts, A. (2014). Fecal microbiota transplantation in: developing human gut microbiota as a class of therapeutics. Nat. Rev. Gastroenterol. Hepatol. 11, 79-80. doi: 10.1038/nrgastro.2013.231

Khoruts, A., and Weingarden, A. R. (2014). Emergence of fecal microbiota transplantation as an approach to repair disrupted microbial gut ecology. Immunol. Lett. 162, 77-81. doi: 10.1016/j.imlet.2014.07.016

Knights, D., Ward, T. L., McKinlay, C. E., Miller, H., Gonzalez, A., McDonald, D., et al. (2014). Rethinking "enterotypes". Cell Host Microbe 16, 433-437. doi: 10.1016/j.chom.2014.09.013

Kohl, K. D., Amaya, J., Passement, C. A., Dearing, M. D., and McCue, M. D. (2014). Unique and shared responses of the gut microbiota to prolonged fasting: a comparative study across five classes of vertebrate hosts. FEMS Microbiol. Ecol. 90, 883-894. doi: 10.1111/1574-6941.12442

Koirala, S., Mears, P., Sim, M., Golding, I., Chemla, Y. R., Aldridge, P. D., et al. (2014). A nutrient-tunable bistable switch controls motility in Salmonella enterica serovar typhimurium. MBio 5:e1611-14. doi: 10.1128/mBio.01611-14

Kollai, M., Bonyhay, I., Jokkel, G., and Szonyi, L. (1994). Cardiac vagal hyperactivity in adolescent anorexia nervosa. Eur. Heart J. 15, 1113-1118. doi: 10.1093/oxfordjournals.eurheartj.a060636

Korpela, K., Salonen, A., Virta, L. J., Kekkonen, R. A., Forslund, K., Bork, P., et al. (2016). Intestinal microbiome is related to lifetime antibiotic use in Finnish pre-school children. Nat. Commun. 7:10410. doi: 10.1038/ncomms10410

Krogius-Kurikka, L., Lyra, A., Malinen, E., Aarnikunnas, J., Tuimala, J., Paulin, L., et al. (2009). Microbial community analysis reveals high level phylogenetic alterations in the overall gastrointestinal microbiota of diarrhoeapredominant irritable bowel syndrome sufferers. BMC Gastroenterol. 9:95. doi: 10.1186/1471-230X-9-95

Kuhn, K. A., Pedraza, I., and Demoruelle, M. K. (2014). Mucosal immune responses to microbiota in the development of autoimmune disease. Rheumatic Dis. Clin. North Am. 40, 711-725. doi: 10.1016/j.rdc.2014.07.013

Lagier, J.-C., Edouard, S., Pagnier, I., Mediannikov, O., Drancourt, M., and Raoult, D. (2015). Current and past strategies for bacterial culture in clinical microbiology. Clin. Microbiol. Rev. 28, 208-236. doi: 10.1128/CMR.00110-14

Lagier, J.-C., Khelaifia, S., Alou, M. T., Ndongo, S., Dione, N., Hugon, P., et al. (2016). Culture of previously uncultured members of the human gut microbiota by culturomics. Nat. Microbiol. 1:16203. doi: 10.1038/nmicrobiol.2016.203

Lagkouvardos, I., Overmann, J., and Clavel, T. (2017). Cultured microbes represent a substantial fraction of the human and mouse gut microbiota. Gut Microbes. doi: 10.1080/19490976.2017.1320468. [Epub ahead of print].

Lamichhane-Khadka, R., Kwiatkowski, A., and Maier, R. J. (2010). The Hyb hydrogenase permits hydrogen-dependent respiratory growth of Salmonella enterica serovar Typhimurium. MBio 1:e00284-10. doi: 10.1128/mBio.00284-10

Langhans, W. (2000). Anorexia of infection: current prospects. Nutrition 16, 996-1005. doi: 10.1016/S0899-9007(00)00421-4

Larsson, E., Tremaroli, V., Lee, Y. S., Koren, O., Nookaew, I., Fricker, A., et al. (2012). Analysis of gut microbial regulation of host gene expression along the length of the gut and regulation of gut microbial ecology through MyD88. Gut 61, 1124-1131. doi: 10.1136/gutjnl-2011-301104

Lecomte, V., Kaakoush, N. O., Maloney, C. A., Raipuria, M., Huinao, K. D., Mitchell, H. M., et al. (2015). Changes in gut microbiota in rats fed a high fat diet correlate with obesity-associated metabolic parameters. PLoS ONE 10:e0126931. doi: 10.1371/journal.pone.0126931

Ley, R. E., Backhed, F., Turnbaugh, P., Lozupone, C. A., Knight, R. D., and Gordon, J. I. (2005). Obesity alters gut microbial ecology. Proc. Natl. Acad. Sci. U.S.A. 102, 11070-11075. doi: 10.1073/pnas.0504978102 
Ley, R. E., Lozupone, C. A., Hamady, M., Knight, R., and Gordon, J. I. (2008). Worlds within worlds: evolution of the vertebrate gut microbiota. Nat. Rev. Microbiol. 6, 776-788. doi: 10.1038/nrmicro1978

Ley, R. E., Turnbaugh, P. J., Klein, S., and Gordon, J. I. (2006). Microbial ecology: human gut microbes associated with obesity. Nature 444, 1022-1023. doi: $10.1038 / 4441022 \mathrm{a}$

Ling, L. L., Schneider, T., Peoples, A. J., Spoering, A. L., Engels, I., Conlon, B. P., et al. (2015). A new antibiotic kills pathogens without detectable resistance. Nature 517, 455-459. doi: 10.1038/nature14098

Liu, J. Z., van Sommeren, S., Huang, H., Ng, S. C., Alberts, R., Takahashi, A., et al. (2015). Association analyses identify 38 susceptibility loci for inflammatory bowel disease and highlight shared genetic risk across populations. Nat. Genet. 47, 979-986. doi: 10.1038/ng.3359

Liu, Z., Que, F., Liao, L., Zhou, M., You, L., Zhao, Q., et al. (2014). Study on the promotion of bacterial biofilm formation by a salmonella conjugative plasmid and the underlying mechanism. PLoS ONE 9:e109808. doi: 10.1371/journal.pone.0109808

Loftsdóttir, H. C. B., Söderlund, R., Jinnerot, T., Eriksson, E., Bongcam-Rudloff, E., and Aspán, A. (2017). Dynamics of insertion sequence element IS629 inactivation of verotoxin 2 genes in Escherichia coli O157:H7. FEMS Microbiol. Lett. 364:fnx074. doi: 10.1093/femsle/fnx074

Louis, P., Young, P., Holtrop, G., and Flint, H. J. (2010). Diversity of human colonic butyrate-producing bacteria revealed by analysis of the butyryl-CoA: acetate CoA-transferase gene. Environ. Microbiol. 12, 304-314. doi: 10.1111/j.1462-2920.2009.02066.x

Lourenço, M., Ramiro, R. S., Güleresi, D., Barroso-Batista, J., Xavier, K. B., Gordo, I., et al. (2016). A mutational hotspot and strong selection contribute to the order of mutations selected for during Escherichia coli adaptation to the gut. PLoS Genet. 12:e1006420. doi: 10.1371/journal.pgen.1006420

Lozupone, C. A., Hamady, M., Cantarel, B. L., Coutinho, P. M., Henrissat, B., Gordon, J. I., et al. (2008). The convergence of carbohydrate active gene repertoires in human gut microbes. Proc. Natl. Acad. Sci. U.S.A. 105, 15076-15081. doi: 10.1073/pnas.0807339105

Lozupone, C. A., Stombaugh, J. I., Gordon, J. I., Jansson, J. K., and Knight, R. (2012). Diversity, stability and resilience of the human gut microbiota. Nature 489, 220-230. doi: 10.1038/nature11550

Lupfer, C., Thomas, P. G., and Kanneganti, T. D. (2014). Nucleotide oligomerization and binding domain 20dependent dendritic cell activation is necessary for innate immunity and optimal $\mathrm{CD}^{+}$cell responces to influenza $\mathrm{A}$ virus infection. J. Virol. 88, 8946-8955. doi: 10.1128/JVI.01110-14

Lupp, C., Robertson, M. L., Wickham, M. E., Sekiroy, I., Champion, O. L., and Gaynor, E. C. (2007). Host-mediated inflammation disrupts the intestinal microbiota and promotes the overgrowth of Enterobacteriacaea. Host Microbe 2, 119-129. doi: 10.1016/j.chom.2007.06.010

Lurie-Weinberger, M. N., and Gophna, U. (2015). Archaea in and on the human body: health implication and future directions. PLoS Pathog. 11:e1004833. doi: 10.1371/journal.ppat.1004833

Lyte, M., Varcoe, J. J., and Bailey, M. T. (1998). Anxiogenic effect of subclinical bacterial infection in mice in the absence of overt immune activation. Physiol. Behav. 65, 63-68. doi: 10.1016/S0031-9384(98)00145-0

Lyte, M., Vulchanova, L., and Brown, D. R. (2011). Stress at the intestinal surface: catecholamines and mucosa-bacteria interactions. Cell Tissue Res. 343, 23-32. doi: 10.1007/s00441-010-1050-0

MacKie, R. I. (2002). Mutualistic fermentative digestion in the gastrointestinal tract: diversity and evolution. Integr. Comp. Biol. 42, 319-326. doi: 10.1093/icb/42.2.319

MacPherson, A. J., and Uhr, T. (2004). Induction of protective IgA by intestinal dendritic cells carrying commensal bacteria. Science 303, 1662-1665. doi: 10.1126/science.1091334

Maier, L., Barthel, M., Stecher, B., Maier, R. J., Gunn, J. S., and Hardt, W.-D. (2014). Salmonella Typhimurium strain ATCC14028 requires H2-hydrogenases for growth in the gut, but not at systemic sites. PLOS ONE 9:e110187. doi: 10.1371/journal.pone.0110187

Maier, L., Vyas, R., Cordova, C. D., Lindsay, H., Schmidt, T. S. B., Brugiroux, S., et al. (2013). Microbiota-derived hydrogen fuels Salmonella typhimurium invasion of the gut ecosystem. Cell Host Microbe 14, 641-651. doi: 10.1016/j.chom.2013.11.002

Maloney, J., Keselman, A., Li, E., and Singer, S. M. (2015). Macrophages expressing arginase 1 and nitric oxide synthase 2 accumulate in the small intestine during Giardia lamblia infection. Microbes. Infect. 17, 462-467. doi: 10.1016/j.micinf.2015.03.006

Martens, E. C., Lowe, E. C., Chiang, H., Pudlo, N. A., Wu, M., McNulty, N. P., et al. (2011). Recognition and degradation of plant cell wall polysaccharides by two human gut symbionts. PLoS Biol. 9:e1001221. doi: 10.1371/journal.pbio.1001221

Martinez, I., Lattimer, J. M., Hubach, K. L., Case, J. A., Yang, J., Weber, C. G., et al. (2013). Gut microbiome composition is linked to whole grain-induced immunological improvements. ISME J. 792, 269-280. doi: 10.1038/ismej.2012.104

Martinon, F., Mayor, A., and Tschopp, J. (2009). The inflammasomes: guardians of the body. Annu. Rev. Immunol. 27, 229-265. doi: 10.1146/annurev.immunol.021908.132715

Meehan, C. J., and Beiko, R. G. (2014). A phylogenomic view of ecological specialization in the lachnospiraceae, a family of digestive tract-associated bacteria. Genome Biol. Evol. 6, 703-713. doi: 10.1093/gbe/evu050

Messaoudi, M., Lalonde, R., Violle, N., Javelot, H., Desor, D., Nejdi, A., et al. (2011). Assessment of psychotropic-like properties of a probiotic formulation (Lactobacillus helveticus R0052 and Bifidobacterium longum R0175) in rats and human subjects. Br. J. Nutr. 105, 755-764. doi: 10.1017/S0007114510004319

Miettinen, M., Pietilä, T. E., Kekkonen, R. A., Kankainen, M., Latvala, S., Pirhonen, J., et al. (2012). Nonpathogenic Lactobacillus rhamnosus activates the inflammasome and antiviral responses in human macrophages. Gut Microbes. 3, 510-522. doi: 10.4161/gmic. 21736

Miras, A. D., and le Roux, C. W. (2013). Mechanisms underlying weight loss after bariatric surgery. Nat. Rev. Gastroenterol. Hepatol. 10, 575-584. doi: 10.1038/nrgastro.2013.119

Moayyedi, P., Marshall, J. K., Yuan, Y., and Hunt, R. (2014). Canadian association of gastroenterology position statement: fecal microbiota transplant therapy. Can. J. Gastroenterol. Hepatol. 28, 66-68. doi: 10.1155/2014/346590

Mohan, R., Koebnick, C., Schildt, J., Schmidt, S., Mueller, M., and Possner, M., et al. (2006). Effects of Bifidobacterium lactis Bb12 supplementation on intestinal microbiota of preterm infants: a double-blind, placebo-controlled, randomized study. J. Clin. Microbiol. 44, 4025-4031. doi: 10.1128/JCM.00767-06

Moloney, R. D., Desbonnet, L., Clarke, G., Dinant, G., and Cryan, J. F. (2014). The microbiome: stress, health and disease. Mamm. Genome. 25, 49-74. doi: 10.1007/s00335-013-9488-5

Moore, P. S., and Chang, Y. (2010). Why do viruses cause cancer? Highlights of the first century of human tumour virology. Nat. Rev. Cancer 10, 878-889. doi: $10.1038 /$ nrc2961

Moos, W. H., Faller, D. V., Harpp, D. N., Kanara, I., Pernokas, J., Powers, W. R., et al. (2016). Microbiota and neurological disorders: a gut feeling. Biores. Open Access. 5, 137-145. doi: 10.1089/biores.2016.0010

Morotomi, M., and Mutai, M. (1986). In vitro binding of potent mutagenic pyrolysates to intestinal bacteria. J. Natl. Cancer Inst. 77, 195-201.

Mu, C., Yang, Y., and Zhu, W. (2016). Gut microbiota: the brain peacekeeper. Front. Microbiol. 7:345. doi: 10.3389/fmicb.2016.00345

Mukherjee, S., Zheng, H., Derebe, M. G., Callenberg, K. M., Partch, C. L., Rollins, D., et al. (2013). Antibacterial membrane attack by a pore-forming intestinal C-type lectin. Nature 505, 103-107. doi: 10.1038/nature12729

Murtaza, B., Berrichi, M., Bennamar, C., Tordjmann, T., Djeziri, F. Z., Hichami, A., et al. (2017). Zizyphin modulates calcium signalling in human taste bud cells and fat taste perception in the mouse. Fund. Clin. Pharmacol. doi: $10.1111 /$ fcp.12289. [Epub ahead of print].

Nam, Y. D., Kim, H. J., Seo, J. G., Kang, S. W., and Bae, J. W. (2013). Impact of pelvic radiotherapy on gut microbiota of gynecological cancer patients revealed by massive pyrosequencing. PLoS ONE 8:e82659. doi: 10.1371/journal.pone.0082659

Nedialkova, L. P., Denzler, R., Koeppel, M. B., Diehl, M., Ring, D., Wille, T., et al. (2014). Inflammation fuels colicin Ib-dependent competition of Salmonella serovar typhimurium and E. coli in enterobacterial blooms. PLoS Pathog. 10:e1003844. doi: 10.1371/journal.ppat.1003844

Nehra, V., Allen, J. M., Mailing, L. J., Kashyap, P. C., and Woods, J. A. (2016). Gut microbiota: modulation of host physiology in obesity. Physiology 31, 327-335. doi: 10.1152/physiol.00005.2016

Ng, K. M., Ferreyra, J. A., Higginbottom, S. K., Lynch, J. B., Kashyap, P. C., Gopinath, S., et al. (2013). Microbiota-liberated host sugars facilitate post-antibiotic expansion of enteric pathogens. Nature 502, 96-99. doi: $10.1038 /$ nature 12503 
National Heart, Lung, and Blood Institute, NIH (2014). What is Asthma? Available online at: nhlbi.nih.gov/health/health-topics/topics/asthma/

O’Keefe, S. J., Li, J. V., Lahtu, L., Ou, J., Carbonero, F., Mohammed, K., et al. (2015). Fat, fibre and cancer risk in African Americans and rural Africans. Nat. Commun. 6:6342. doi: 10.1038/ncomms7342

Obata, Y., and Pachnis, V. (2016). The effect of microbiota and the immune system on the development and organization of the enteric nervous system. Gastroenterology. 151, 836-844. doi: 10.1053/j.gastro.2016.07.044

Obermeier, F., Dunger, N., Strauch, U. G., Hofmann, C., and Bleich, A. (2005). CpG motifs of bacterial DNA essentially contribute to the perpetuation of chronic intestinal inflammation. Gastroenterology 129, 913-927. doi: 10.1053/j.gastro.2005.06.061

Olson, C. K., Ethelberg, S., van Pelt, W., and Tauxe, R. V. (2008). "Epidemiology of Campylobacter jejuni infections in industrialized nations," in Campylobacter, $3 r d E d n$, eds I. Nachamkin, C. Szymanski, and M. Blaser (Washington, DC: ASM Press).

Ortega, Y. R., and Sanchez, R. (2010). Update on Cyclospora cayetanensis, A food-borne and waterborne parasite. Clin. Microbiol. Rev. 23, 218-234. doi: 10.1128/CMR.00026-09

Ott, S. J., Musfeldt, M., Wenderoth, D. F., Hampe, J., Brandt, O., Fölsch, U. R., et al (2004). Reduction in diversity of the colonic mucosa associated bacterial microflora in patients with active inflammatory bowel disease. Gut 53, 685-693. doi: $10.1136 /$ gut.2003.025403

Pacheco, A. R., Curtis, M. M., Ritchie, J. M., Munera, D., Waldor, M. K., Moreira, C. G., et al. (2012). Fucose sensing regulates bacterial intestinal colonization. Nature 492, 113-117. doi: 10.1038/nature11623

Park, J. H., Peyrin-Biroulet, L., Eisenhut, M., and Shin, J. I. (2017). IBD immunopathogenesis: a comprehensive review of inflammatory molecules. Autoimmun. Rev. 16, 416-426. doi: 10.1016/j.autrev.2017.02.013

Patrascu, O., Béguet-Crespel, F., Marinelli, L., Chatelier, E. L., Abraham, A.L., Leclerc, M., et al. (2017). A fibrolytic potential in the human ileum mucosal microbiota revealed by functional metagenomic. Sci. Rep. 7:40248. doi: $10.1038 /$ srep 40248

Patwa, L. G., Fan, T. J., Tchaptchet, S., Liu, Y., Lussier, Y. A., Sartor, R. B., et al. (2011). Chronic intestinal inflammation induces stress-response genes in commensal Escherichia coli. Gastroenterology 141, 1842-1851. doi: 10.1053/j.gastro.2011.06.064

Pickard, J. M., Maurice, C. F., Kinnebrew, M. A., Abt, M. C., Schenten, D., Golovkina, T. V., et al. (2014). Rapid fucosylation of intestinal epithelium sustains host-commensal symbiosis in sickness. Nature 514, 638-641. doi: $10.1038 /$ nature 13823

Prabhu, V., and Shivani, A. (2014). An overview of history, pathogenesis and treatment of perforated peptic ulcer disease with evaluation of prognosis scoring in adults. Ann. Med. Health Sci. Res. 4, 22-29. doi: 10.4103/2141-9248.126604

Prentice, A. M., Nabwera, H., Kwambana, B., Antonio, M., and Moore, S. E. (2013). Microbes and the malnourished child. Sci. Transl. Med. 5:180fs11. doi: $10.1126 /$ scitranslmed.3006212

Pugsley, A. P., and Reeves, P. (1976). Iron uptake in colicin B-resistant mutants of Escherichia coli K-12. J. Bacteriol. 126, 1052-1062.

Qin, J., Li, R., Raes, J., Arumugam, M., Burgdorf, K. S., Manichanh, C., et al. (2010). A human gut microbial gene catalogue established by metagenomic sequencing. Nature 464, 59-65. doi: 10.1038/nature08821

Rabsch, W., Tschape, H., and Baumler, A. J. (2001). Non-typhoidal salmonellosis: emerging problems. Microbes Infect. 3, 237-247. doi: 10.1016/S1286-4579(01)01375-2

Raffatellu, M., Georgy, M. D., Akiyama, Y., Hornsby, M. J., Nuccio, S. P., Paixao, T. A., et al. (2009). Lipocalin-2 resistance confers an advantage to Salmonella enterica serotype Typhimurium forg rowth and survival in the inflamed intestine. Cell Host Microbe 5, 476-486. doi: 10.1016/j.chom.2009.03.011

Rajilić-Stojanović, M., Biagi, E., Heilig, H. G., Kajander, K., Kekkonen, R. A., Tims, S., et al. (2011). Global and deep molecular analysis of microbiota signatures in fecal samples from patients with irritable bowel syndrome. Gastroenterology 141, 1792-1801. doi: 10.1053/j.gastro.2011.07.043

Ramirez-Farias, C., Slezak, K., Fuller, Z., Duncan, A., Holtrop, G., and Louis, P. (2009). Effect of inulin on the human gut microbiota: stimulation of Bifidobacterium adolescentis and Faecalbacterium prausnitzii. Br. J. Nutr. 101, 541-550. doi: 10.1017/S0007114508019880

Rausch, P., Rehman, A., Kunzel, S., Hasler, R., Ott, S. J., Schreiber, S., et al. (2011). Colonic mucosa-associated microbiota is influenced by an interaction of Crohn disease and FUT2 (Secretor) genotype. Proc. Natl. Acad. Sci. U.S.A. 108, 19030-19035. doi: 10.1073/pnas.1106408108

Rawls, J. F., Samuel, B. S., and Gordon, J. I. (2004). From The Cover: Gnotobiotic zebrafish reveal evolutionarily conserved responses to the gut microbiota. Proc. Natl. Acad. Sci. U.S.A. 101, 4596-4601. doi: 10.1073/pnas.0400706101

Ray, D., and Kidane, D. (2016). Gut microbiota imbalance and base excision repair dynamics in colon cancer. J. Cancer 7, 1421-1430. doi: 10.7150/jca.15480

Reece, J. B., Urry, L. A., Cain, M. L., Wasserman, S. A., Minorsky, P. V., and Jackson, R. B. (2011). Campbell Biology, 9th Edn. San Francisco, CA: Benjamin Cummings.

Reinhardt, C., Bergentall, M., Greiner, T. U., Schaffner, F., Ostergren-Lunden, G., Peterson, L. C., et al. (2012). Tissue factor and PAR1 promote microbiota-induced intestinal vascular remodelling. Nature 438, 627-631. doi: $10.1038 /$ nature 10893

Rhee, S. H., Pothoulakis, C., and Mayer, E. A. (2009). Principles and clinical implications of the brain-gut-enteric microbiota axis. Nat. Rev. Gastroenterol. 6, 306-314. doi: 10.1038/nrgastro.2009.35

Rigottier-Gois, L., Madec, C., Navickas, A., Matos, R. C., Akary-Lepage, E., Mistou, M.-Y., et al. (2015). The surface rhamnopolysaccharide epa of enterococcus faecalis is a key determinant of intestinal colonization. J. Infect. Dis. 211, 62-71. doi: 10.1093/infdis/jiu402

Robosky, L. C. (2005). Metabonomic identification of two distinct phenotypes in sprague-dawley (Crl:CD(SD)) rats. Toxicol. Sci. 87, 277-284. doi: $10.1093 /$ toxsci/kfi214

Rohde, C. M., Wells, D. F., Robosky, L. C., Manning, M. L., Clifford, C. B., Reily, M. D., et al. (2007). Metabonomic evaluation of schaedler altered microflora rats. Chem. Res. Toxicol. 20, 1388-1392 doi: 10.1021/tx700184u

Rosenberg, E., and Zilber-Rosenberg, I. (2013). The Hologenome Concept: Human, Animal and Plant Microbiota (Basel: Springer International Publishing).

Round, J. L., and Mazmanian, S. K. (2009). The gut microbiota shapes intestinal immune responses during health and disease. Nat. Rev. Immunol. 9, 313-323. doi: $10.1038 /$ nri2515

Russell, A. B., Wexler, A. G., Harding, B. N., Whitney, J. C., Bohn, A. J., Goo, Y. A., et al. (2014). A type VI secretion-related pathway in Bacteroidetes mediates interbacterial antagonism. Cell Host Microbe 16, 227-236. doi: 10.1016/j.chom.2014.07.007

Salonen, A., Lahti, L., Salojärvi, J., Holtrop, G., Korpela, K., Duncan, S. H., et al. (2014). Impact of diet and individual variation on intestinal microbiota composition and fermentation products in obese men. ISME J. 8, 2218-2230. doi: 10.1038 /ismej. 2014.63

Satoh-Takayama, N., Vosshenrich, C. A., Lesjean-Pottier, S., Sawa, S., Lochner, M., Rattis, F., et al. (2008). Microbial flora drives interleukin 22 production in intestinal NKp46 cells that provide innate mucosal immune defense. Immunity 29, 958-970. doi: 10.1016/j.immuni.2008.11.001

Saxelin, M., Lassig, A., Karjalainen, H., Tynkkynen, S., Surakka, A., Vapaatalo, H., et al. (2010). Persistence of probiotic strains in the gastrointestinal tract when administered as capsules, yoghurt, or cheese. Int. J. Food Microbiol. 144, 293-300. doi: 10.1016/j.ijfoodmicro.2010.10.009

Schirbel, A., and Fiocchi, C. J. (2010). Inflammatory bowel disease: established and evolving considerations on its etiopathogenesis and therapy. Dig. Dis. 11, 266-276. doi: 10.1111/j.1751-2980.2010.00449.x

Schloissnig, S., Arumugam, M., Sunagawa, S., Mitreva, M., Tap, J., Zhu, A., et al. (2013). Genomic variation landscape of the human gut microbiome. Nature 493, 45-50. doi: 10.1038/nature11711

Schneeman, B. O. (2002). Gastrointestinal physiology and functions. Brit. J. Nutr. 88(Suppl. 2), S159-S163. doi: 10.1079/BJN2002681

Schnorr, S. L., and Bachner, H. A. (2016). Integrative therapies in anxiety treatment with special emphasis on the gut microbiome. Yale J. Biol. Med. 89, 397-422.

Schnorr, S. L., Candela, M., Rampeli, S., Centanni, M., Concolandi, C., Basaglia, G., et al. (2014). Gut microbiome of the Hadza hunter-gatherers. Nat. Commun. 5, 3654. doi: $10.1038 /$ ncomms 4654

Schwabe, R. F., and Jobin, C. (2013). The microbiome and cancer. Nat. Rev. Cancer 13, 800-812. doi: $10.1038 / \mathrm{nrc} 3610$

Seekatz, A. M., Aas, J., Gessert, C. E., Rubin, T. A., Saman, D. M., Bakken, J. S., et al. (2014). Recovery of the gut microbiome following fecal microbiota transplantation. MBio 5:e00893-14. doi: 10.1128/mBio.00893-14

Sen, T., Carolina, R., Cawthon, C. R., Ihde, B. T., Hajnal, A., Dilorenzo, P. M., et al. (2017). Diet-driven microbiota dysbiosis is associated with vagal remodeling and obesity. Physiol. Behav. 173, 305-317. doi: 10.1016/j.physbeh.2017. 02.027 
Seng, P., Abat, C., Rolain, J. M., Colson, P., Lagier, J. C., Gouriet, F., et al. (2013). Identification of rare pathogenic bacteria in a clinical microbiology laboratory: impact of matrix-assisted laser desorption ionization- time of flight mass spectrometry. J. Clin. Microbiol. 51, 2182-2194. doi: 10.1128/JCM.00492-13

Shang, Y., Khafipour, E., Derakhshani, H., Sarna, L. K., Woo, C. W., and Siow, Y. L., (2017). Short term high fat diet induces obesity-enhancing changes in mouse gut microbiota that are partially reversed by cessation of the high fat diet. Lipids 52, 499-511. doi: 10.1007/s11745-017-4253-2

Shankar, V., Hamilton, M. J., Khoruts, A., Kilburn, A., Unno, T., Paliy, O., et al. (2014). Species and genus level resolution analysis of gut microbiota in Clostridium difficile patients following fecal microbiota transplantation. Microbiome 2:13. doi: 10.1186/2049-2618-2-13

Sheridan, P. O., Martin, J. C., Lawley, T. D., Browne, H. P., Harris, H. M., BernalierDonadile, A., et al. (2016). Polysaccharide utilization loci and nutritional specialization in a dominant group of butyrate-producing human colonic Firmicutes. Microb. Genom. 2:e000043. doi: 10.1099/mgen.0.000043

Shi, N., Li, N., Duan, X., and Niu, H. (2017). Interaction between the gut microbiome and mucosal immune system. Military Med. Res. 4:14. doi: 10.1186/s40779-017-0122-9

Shim, J. (2013). Gut microbiota in inflammatory bowel disease. Pediatr. Gastroenterol. Hepatol. Nutr. 16, 17-21. doi: 10.5223/pghn.2013.16.1.17

Singh, V., Chassaing, B., Zhang, L., San Yeoh, B., Xiao, X., Kumar, M., et al. (2015). Microbiota-dependent hepatic lipogenesis mediated by stearoyl CoA Desaturase 1 (SCD1) Promotes Metabolic Syndrome in TLR5-Deficient Mice. Cell Metab. 22, 983-996. doi: 10.1016/j.cmet.2015.09.028

Smith, M. I., Yatsunenko, T., Manary, M. J., Trehan, I., Mkakosya, R., Cheng, J., et al. (2013). Gut microbiomes of malawian twin pairs discordant for kwashiorkor. Science 339, 548-554. doi: 10.1126/science. 1229000

Smythies, L. E., Sellers, M., Clements, R. H., Mosteller-Barnum, M., Meng, G., Benjamin, W. H., et al. (2005). Human intestinal macrophages display profound inflammatory anergy despite avid phagocytic and bacteriocidal activity. J. Clin. Invest. 115, 66-75. doi: 10.1172/JCI200519229

Sommer, F., and Bäckhed, F. (2013). The gut microbiota - masters of host development and physiology. Nat. Rev. Microbiol. 11, 227-238. doi: 10.1038/nrmicro2974

Sonnenberg, G. F., Monticelli, L. A., Elloso, M. M., Fouser, L. A., and Artis, D. (2011). CD4 lymphoid tissue-inducer cells promote innate immunity in the gut. Immunity 34, 122-134. doi: 10.1016/j.immuni.2010.12.009

Sonnenburg, E. D., and Sonnenburg, J. L. (2014). Gut microbes take their vitamins. Cell Host Microbe 15, 5-6. doi: 10.1016/j.chom.2013.12.011

Stappenbeck, T. S., Hooper, L. V., and Gordon, J. I. (2002). Developmental regulation of intestinal angiogenesis by indigenous microbe via Paneth Cells. Proc. Natl. Acad. Sci. U.S.A. 99, 15451-15455. doi: 10.1073/pnas.202604299

Stecher, B. (2013). Finding a sugary foothold: how antibiotics pave the way for enteric pathogens. Cell Host Microbe 14, 225-227. doi: 10.1016/j.chom.2013.08.008

Strachan, D. P. (1989). Hay fever, hygiene, and household size. BMJ 299, 1259-1260. doi: 10.1136/bmj.299.6710.1259

Subramanian, S., Huq, S., Yatsunenko, T., Haque, R., Mahfuz, M., Alam, M. A., et al. (2014). Persistent gut microbiota immaturity in malnourished Bangladeshi children. Nature 510, 417-421. doi: 10.1038/nature13421

Sudo, N. (2006). Stress and gut microbiota: does postnatal microbial colonization programs the hypothalamic-pituitary-adrenal system for stress response? Psychosom. Med. 1287, 350-354. doi: 10.1016/j.ics.2005.12.019

Suzuki, M., Suzuki, H., Masaoka, T., Tanaka, S., Suzuki, K., and Ishii, H. (2004). Helicobacter pylori eradication treatment modulates epithelial cell proliferation and tissue content of hepatocyte growth factor in the gastric mucosa. Aliment. Pharmacol. Ther. 20(Suppl. 1), 158-164. doi: 10.1111/j.1365-2036.2004.01971.x

Tamboli, C. P., Neut, C., Desreumaux, P., and Colombel, J. F. (2004). Dysbiosis in inflammatory bowel disease. Gut 53, 1-4. doi: 10.1136/gut.53.1.1

Tao, J., Sang, Y., Teng, Q., Ni, J., Yang, Y., Tsui, S. K.-W., et al. (2015). Heat shock proteins IbpA and IbpB are required for NlpI-participated cell division in Escherichia coli. Front. Microbiol. 6:51. doi: 10.3389/fmicb.2015. 00051

Thaiss, C. A., Levy, M., Korem, T., Dohnalova, L., Shapiro, H., Jaitin, D. A., et al. (2016a). Microbiota diurnal rhythmicity programs host transcriptome oscillations. Cell 167, 1495-1510. doi: 10.1016/j.cell.2016.11.003
Thaiss, C. A., Zmora, N., Levy, M., and Elinav, E. (2016b). The microbiome and innate immunity. Nature 535, 65-74. doi: 10.1038/nature18847

Thomas, M. T., Shepherd, M., Poole, R. K., van Vliet, A. H, Kelly, D. J., and Pearson, B. M. (2011). Two respiratory enzyme systems in Campylobacter jejuni NCTC 11168 contribute to growth on l-lactate. Environ. Microbiol. 13, 48-61. doi: 10.1111/j.1462-2920.2010.02307.x

Tilg, H., and Moschen, A. R. (2013). Gut microbiota: malnutrition and microbiota-a new relationship? Nat. Rev. Gastroenterol. Hepatol. 10, 261-262. doi: 10.1038/nrgastro.2013.48

Topping, D. L., and Clifton, P. M. (2001). Short-chain fatty acids and human colonic function: roles of resistant atarch and nonstarch polysaccharides. Physiol. Rev. 81, 1031-1064.

Trehan, I., Goldbach, H. S., Lagrone, L. N., Meuli, G. J., Wang, R. J., Maleta, K. M., et al. (2013). Antibiotics as part of the management of severe acute malnutrition. N. Engl. J. Med. 368, 425-435. doi: 10.1056/NEJMoa1202851

Trinchieri, G. (2012). Cancer and inflammation: an old intuition with rapidly evolving new concepts. Annu. Rev. Immunol. 30, 677-706. doi: 10.1146/annurev-immunol-020711-075008

Tumanov, A. V., Koroleva, E. P., Guo, X., Wang, Y., Kruglov, A., Nedospasov, S., et al. (2011). Lymphotoxin controls the IL-22 protection pathway in gut innate lymphoid cells during mucosal pathogen challenge. Cell Host Microbe 10, 44-53. doi: 10.1016/j.chom.2011.06.002

Turnbaugh, P. J., Ley, R. E., Hamady, M., Fraser-Liggett, C., Knight, R., and Gordon, J. I. (2007). The human microbiome project: exploring the microbial part of ourselves in a changing world. Nature 449, 804-810. doi: $10.1038 /$ nature 06244

Turnbaugh, P. J., Ley, R. E., Mahowald, M. A., Magrini, V., Mardis, E. R., and Gordon, J. I. (2006). An obesity-associated gut microbiome with increased capacity for energy harvest. Nature 444, 1027-1131. doi: 10.1038/nature05414

Vaarala, O., Atkinson, M. A., and Neu, J. (2008). The 'perfect storm' for type 1 diabetes: the complex interplay between intestinal microbiota, gut permeability, and mucosal immunity. Diabetes 57, 2555-2562. doi: 10.2337/db08-0331

Van der Waaij, D., Berghuis-de Vries, J. M., and Lekkerkerk-Van der Wees, J. E. C. (1971). Colonization resistance of the digestive tract in conventional and antibiotic-treated mice. J. Hygiene 69, 405-411. doi: 10.1017/S0022172400021653

van Nood, E., Vrieze, A., Nieuwdorp, M., Fuentes, S., Zoetendal, E. G., Vos, W. M. D., et al. (2013). Duodenal infusion of donor feces for recurrent Clostridium difficile. N. Engl. J. Med. 368, 407-415. doi: 10.1056/NEJMoa1205037

Vaughn, A. C., Cooper, E. M., DiLorenzo, P. M., O’Loughlin, L. J., Konkel, M. E., Peters, J. H., et al. (2017). Energy-dense diet triggers changes in gut microbiota, reorganization of gut-brain vagal communication and increases body fat accumulation. Acta Neurobiol. Exp. (Wars) 77, 18-30.

Vercelli, D. (2009). Gene-environment interactions: the road less traveled by in asthma genetics. J. Allergy Clin. Immunol. 123, 26-27. doi: 10.1016/j.jaci.2008.11.031

Vercelli, D. (2010). Gene-environment interactions in asthma and allergy: the end of the beginning? Curr. Opin. Allergy Clin. Immunol. 10, 145-148. doi: 10.1097/ACI.0b013e32833653d7

Vernocchi, P., Del Chierico, F., and Putignani, L. (2016). Gut microbiota profiling: metabolomics based approach to unravel compounds. Front. Microbiol. 7:1144. doi: $10.3389 /$ fmicb.2016.01144

Virchow, R. (1863). “Aetiologie der neoplastichen Geschwuelte," in Die krankhaften Geschwülste, ed R. Virchow (Berlin: Verlag von August von Hirschwald), 57-101.

Von Mutius, E., Vercelli, D. (2010). Farm living: effects on childhood asthma and allergy. Nat. Rev. Immunol. 10, 861-868. doi: 10.1038/nri2871

Voreades, N., Kozil, A., and Weir, T. L. (2014). Diet and the development of the human intestinal microbiome. Front. Microbiol. 5:494. doi: 10.3389/fmicb.2014.00494

Wacklin, P., Mäkivuokko, H., Alakulppi, N., Nikkilä, J., Tenkanen, H., Räbinä, J., et al. (2011). Secretor genotype (FUT2 gene) is strongly associated with the composition of bifidobacteria in the human intestine. PLOS ONE 6:e20113. doi: 10.1371/journal.pone.0020113

Wagner, S., Beil, W., Westermann, J., Logan, R. P., Bock, C. T., Trautwein, C., et al. (1997). Regulation of gastric epithelial cell growth by Helicobacter pylori: evidence for a major role of apoptosis. Gastroenterology 113, 1836-1847. doi: 10.1016/S0016-5085(97)70003-9 
Walker, A. W., Ince, J., Duncan, S. H., Webster, L. M., Holtrop, G., Ze, X., et al. (2011). Dominant and diet-responsive groups of bacteria within the human colonic microbiota. ISME J. 5, 220-230. doi: 10.1038/ismej.2010.118

Walker, A. W., Sanderson, J. D., Churcher, C., Parkes, G. C., Hudspith, B. N., Rayment, N., et al. (2010). High-throughput clone library analysis of the mucosa-associated microbiota reveals dysbiosis and differences between inflamed and non-inflamed regions of the intestine in inflammatory bowel disease. BMC Microbiol. 11:7. doi: 10.1186/1471-2180-11-7

Wallace, J. L., Syer, S., Denou, E., de Palma, G., Vong, L., McKnight, W., et al. (2011). Proton pump inhibitors exacerbate NSAID-induced small intestine injury by inducing dysbiosis. Gastroenterology 141, 1314-1322. doi: 10.1053/j.gastro.2011.06.075

Walters, W. A., Xu, Z., and Knight, R. (2014). Meta-analyses of human gut microbes associated with obesity and IBD. FEBS Lett. 588, 4223-4233. doi: 10.1016/j.febslet.2014.09.039

Wang, F., Meng, W., and Wang, B. (2014). Helicobacter pylori-induced gastric inflammation and gastric cancer. Cancer Lett. 345, 196-202. doi: 10.1016/j.canlet.2013.08.016

Wang, X., Heazlewood, S., Krause, D., and Florin, T. (2003). Molecular characterization of the microbial species that colonize human ileal and colonic mucosa by using $16 \mathrm{~S}$ rDNA sequence analysis. J. Appl. Microbiol. 95, 508-520. doi: 10.1046/j.1365-2672.2003.02005.x

Wassenaar, T., Beimfohr, C., Geske, T., and Zimmermann, K. (2014). Voluntarily exposure to a single, high dose of probiotic Escherichia coli results in prolonged colonisation. Benef. Microbes. 5, 367-375. doi: 10.3920/BM2013.0087

Weber, J., Illi, S., Nowak, D., Schierl, R., Holst, O., Mutius, E. V., et al. (2015). Asthma and the hygiene hypothesis. does cleanliness matter? Am. J. Respir. Crit. Care Med. 191, 522-529. doi: 10.1164/rccm.201410-1899OC

Wehkamp, J., Salzman, N. H., Porter, E., Nuding, S., Weichenthal, M., Petras, R. E., et al. (2005). Reduced paneth cell a-defensins and antimicrobial activity in ileal crohn's disease. Inflamm. Bowel Dis. 102, 18129-18134. doi: 10.1097/00054725-200604002-00040

WHO (2014). Antimicrobial Resistance Global Report. Geneva. Available online at: http://apps.who.int/iris/bitstream/10665/112642/1/9789241564748_eng.pdf (Accessed May 10, 2017).

WHO (2016). Salmonella (Non-typhoidal). Geneva: World Health Organization. Available online at: http://www.who.int/mediacentre/factsheets/fs139/en/ (Accessed April 6, 2017).

WHO (2007). Community-Based Management of Severe Acute Malnutrition. Geneva: WHO/WFP/UNSCN/UNICEF.

Wills-Karp, M., Santeliz, J., and Karp, C. L. (2001). The germless theory of allergic disease: revisiting the hygiene hypothesis. Nat. Rev. Immunol. 1, 69-75. doi: $10.1038 / 35095579$

Winter, S. E., Thiennimitr, P., Winter, M. G., Butler, B. P., Huseby, D. L., Crawford, R. W., et al. (2010). Gut inflammation provides a respiratory electron acceptor for Salmonella. Nature 467, 426-429. doi: 10.1038/nature09415

Wostmann, B. S., Pleasants, J. R., Bealmear, P., and Kincade, P. W. (1970). Serum proteins and lymphoid tissues in germ-free mice fed a chemically defined, water soluble, low molecular weight diet. Immunology 19, 443-448.

Wroblewski, L. E., Peek, R. M., and Coburn, L. A. (2016). The role of the microbiome in gastrointestinal cancer. Gastroenterol. Clin. North Am. 45, 543-556. doi: 10.1016/j.gtc.2016.04.010

Wu, X., He, B., Liu, J., Feng, H., Ma, Y., and Li, D., et al. (2016). Molecular insight into gut microbiota and rheumatoid arthritis. Int. J. Mol. Sci. 17:431. doi: $10.3390 /$ ijms 17030431

Yamamoto, M., and Matsumoto, S. (2016). Gut microbiota and colorectal cancer. Genes Environ. 38:11. doi: 10.1186/s41021-016-0038-8

Yatsunenko, T., Rey, F. E., Manary, M. J., Trehan, I., Dominguez-Bello, M. H., Contreras, M., et al. (2012). Human gut microbiome viewed across age and geography. Nature 486, 222-227. doi: 10.1038/nature11053

Zainah, H., Hassan, M., Shiekh-Sroujieh, L., Hassan, S., Alangaden, G., and Ramesh, M. (2014). Intestinal microbiota transplantation, a simple and effective treatment for severe and refractory clostridium difficile infection. Dig. Dis. Sci. 60, 181-185. doi: 10.1007/s10620-014-3296-y

Ze, X., Duncan, S. H., Louis, P., and Flint, H. J. (2012). Ruminococcus bromii is a keystone species for the degradation of resistant starch in the human colon. ISME J. 6, 1535-1543. doi: 10.1038/ismej.2012.4
Ze, X., Le Mougen, F., Duncan, S. H., Louis, P., and Flint, H. J. (2013). Some are more equal than others: the role of "keystone" species in the degradation of recalcitrant substrates. Gut Microbes 4, 236-240. doi: 10.4161/gmic. 23998

Zhang, C., Zhang, M., Pang, X., Zhao, Y., Wang, L., and Zhao, L. (2012). Structural resilience of the gut microbiota in adult mice under high-fat dietary perturbations. ISME J. 6, 1848-1857. doi: 10.1038/ismej. 2012.27

Zhang, H., DiBaise, J. K., Zuccolo, A., Kudrna, D., Braidotti, M., Yu, Y., et al. (2009). Human gut microbiota in obesity and after gastric bypass. Proc. Natl. Acad. Sci. U.S.A. 106, 2365-2370. doi: 10.1073/pnas.08126 00106

Zilber-Rosenberg, I., and Rosenberg, E. (2008). Role of microorganisms in the evolution of animals and plants: the hologenome theory of evolution. FEMS Microbiol. Rev. 32, 723-735. doi: 10.1111/j.1574-6976.2008.00123.x

Zuckert, W. R. (2014). Secretion of bacterial lipoproteins: through the cytoplasmic membrane, the periplasm and beyond. Biochim. Biophys. Acta 184, 1509-1516. doi: 10.1016/j.bbamcr.2014.04.022

Zuk, M. (2014). Paleofantasy: What Evolution Really Tells Us About Sex, Diet, and How We Live. New York, NY: WW Norton \& Company.

Conflict of Interest Statement: The authors declare that the research was conducted in the absence of any commercial or financial relationships that could be construed as a potential conflict of interest.

\section{Received: 22 December 2016; Accepted: 23 June 2017; Published: 17 July 2017}

Citation: Selber-Hnatiw S, Rukundo B, Ahmadi M, Akoubi H, Al-Bizri H, Aliu AF, Ambeaghen TU, Avetisyan L, Bahar I, Baird A, Begum F, Ben Soussan H, Blondeau-Éthier V, Bordaries R, Bramwell H, Briggs A, Bui R, Carnevale $M$, Chancharoen M, Chevassus T, Choi JH, Coulombe K, Couvrette F, D'Abreau S, Davies M, Desbiens M-P, Di Maulo T, Di Paolo S-A, Do Ponte S, dos Santos Ribeiro P, Dubuc-Kanary L-A, Duncan PK, Dupuis F, El-Nounou S, Eyangos CN, Ferguson NK, Flores-Chinchilla NR, Fotakis T, Gado Oumarou H D M, Georgiev M, Ghiassy S, Glibetic N, Grégoire Bouchard J, Hassan T, Huseen I, Ibuna Quilatan MF, Iozzo T, Islam S, Jaunky DB, Jeyasegaram A, Johnston M-A, Kahler MR, Kaler K, Kamani C, Karimian Rad H, Konidis E, Konieczny F, Kurianowicz S, Lamothe P, Legros K, Leroux S, Li J, Lozano Rodriguez ME, Luponio-Yoffe S, Maalouf Y, Mantha J, McCormick M, Mondragon P, Narayana T, Neretin E, Nguyen TTT, Niu I, Nkemazem RB, O'Donovan M, Oueis M, Paquette S, Patel N, Pecsi E, Peters J, Pettorelli A, Poirier C, Pompa VR, Rajen H, Ralph R-O, RosalesVasquez J, Rubinshtein D, Sakr S, Sebai MS, Serravalle L, Sidibe F, Sinnathurai A, Soho D, Sundarakrishnan A, Svistkova V, Ugbeye TE, Vasconcelos MS, Vincelli M, Voitovich O, Vrabel P, Wang L, Wasfi M, Zha CY and Gamberi C (2017) Human Gut Microbiota: Toward an Ecology of Disease. Front. Microbiol. 8:1265. doi: 10.3389/fmicb.2017.01265

This article was submitted to Microbial Symbioses, a section of the journal Frontiers in Microbiology

Copyright (c) 2017 Selber-Hnatiw, Rukundo, Ahmadi, Akoubi, Al-Bizri, Aliu, Ambeaghen, Avetisyan, Bahar, Baird, Begum, Ben Soussan, Blondeau-Éthier, Bordaries, Bramwell, Briggs, Bui, Carnevale, Chancharoen, Chevassus, Choi, Coulombe, Couvrette, D'Abreau, Davies, Desbiens, Di Maulo, Di Paolo, Do Ponte, dos Santos Ribeiro, Dubuc-Kanary, Duncan, Dupuis, El-Nounou, Eyangos, Ferguson, Flores-Chinchilla, Fotakis, Gado Oumarou H D, Georgiev, Ghiassy, Glibetic, Grégoire Bouchard, Hassan, Huseen, Ibuna Quilatan, Iozzo, Islam, Jaunky, Jeyasegaram, Johnston, Kahler, Kaler, Kamani, Karimian Rad, Konidis, Konieczny, Kurianowicz, Lamothe, Legros, Leroux, Li, Lozano Rodriguez, Luponio-Yoffe, Maalouf, Mantha, McCormick, Mondragon, Narayana, Neretin, Nguyen, Niu, Nkemazem, O'Donovan, Oueis, Paquette, Patel, Pecsi, Peters, Pettorelli, Poirier, Pompa, Rajen, Ralph, Rosales-Vasquez, Rubinshtein, Sakr, Sebai, Serravalle, Sidibe, Sinnathurai, Soho, Sundarakrishnan, Svistkova, Ugbeye, Vasconcelos, Vincelli, Voitovich, Vrabel, Wang, Wasfi, Zha and Gamberi. This is an open-access article distributed under the terms of the Creative Commons Attribution License (CC BY). The use, distribution or reproduction in other forums is permitted, provided the original author(s) or licensor are credited and that the original publication in this journal is cited, in accordance with accepted academic practice. No use, distribution or reproduction is permitted which does not comply with these terms. 